\title{
Permeability evolution and water transfer in the excavation damaged zone of a ventilated gallery
}

\author{
B. Pardoen ${ }^{\mathrm{a}, 1, *}$, J. Talandier ${ }^{\mathrm{b}}, \mathrm{F}$. Collin $^{\mathrm{a}}$ \\ ${ }^{a}$ ArGEnCo Department, University of Liège, Allée de la Découverte 9, 4000 Liège, Belgium \\ ${ }^{b}$ Fluid and Solid Mechanics Department, Research and Development Division, Andra, Rue \\ Jean Monnet 1-7, 92298 Châtenay-Malabry, France
}

\begin{abstract}
The fluid transfers occurring around underground galleries are of paramount importance when envisaging the long-term sustainability of underground structures for nuclear waste disposal. These transfers are mainly conditioned by the behaviour of the surrounding material and by its interaction with the gallery air. The hydro-mechanical behaviour of the excavation damaged zone, which develops around galleries due to the drilling process, is thenceforward critical because it is composed of fractures having a significant irreversible impact on flow characteristics and transfer kinetics. Besides, the material interaction with the gallery air may engender water drainage and desaturation. Thus, a gallery air ventilation experiment, preceded by its excavation, is numerically modelled in an unsaturated argillaceous rock to study its influence on hydraulic transfers. The fractures are numerically represented with shear strain localisation bands by means of a microstructure enriched model including a regularisation method. The impact of fracturing on the transport properties is addressed by associating the intrinsic permeability increase with mechanical deformation which is amplified in the strain localisation discontinuities. Such dependence permits to reproduce a significant permeability increase of several orders of magnitude in the excavation damaged zone, in agreement with available experimental mea-
\end{abstract}

\footnotetext{
*Corresponding author. Tel.: +32 43662033.

Email address: b.pardoen@ulg.ac.be (B. Pardoen)

${ }^{1}$ FRIA, F.R.S.-FNRS scholarship holder
} 
surements. After the excavation, the hydraulic transfers are studied through the reproduction of a gallery air ventilation experiment that implies drainage and desaturation of the surrounding rock. These transfers depend on liquid water and water vapour exchanges at gallery wall that are introduced through a non-classical boundary condition. The model prediction successfully captures the drainage and desaturation kinetics of undisturbed and damaged rock.

Keywords: Permeability modification, excavation damaged zone, rock-air interaction, unsaturated behaviour, modelling, shear banding

\section{Introduction}

In the context of long-term nuclear waste management, deep underground repository of high-level radioactive waste is envisaged in geological media having good confining characteristics. The behaviour of the surrounding material has

5 to be precisely characterised in order to assess the long-term sustainability of the underground structures. Nowadays, it is commonly assumed that underground drilling process engenders cracks and eventually fractures [1] that deteriorates the hydro-mechanical properties of the surrounding host material. These modifications take place in a zone called Excavation Damaged Zone (EDZ), located

10 around the galleries, which is affected by important modifications of the material flow characteristics such as permeability increase [2]. Since a low hydraulic conductivity is required to ensure a safe long-term disposal, the EDZ behaviour is a major issue because it may constitute a preferential flow path for radionuclide migration. Consequently, the characterisation of the material transport properties and of the transfer kinetics that occur around galleries still need to be investigated.

The flow transfers are also conditioned by the interaction with the gallery air. At repository scale, air ventilation is usually realised in galleries during the excavation and the maintenance phases. This ventilation can affect the material behaviour by draining its water and causing desaturation. Therefore, large-scale air ventilation experiments are performed in Underground Research Laborato- 
ries (URL). The latter have been developed to investigate the suitability of host formations for nuclear waste disposal and to evaluate the repository feasibility [3. A numerical reproduction of an air ventilation test performed in a low permeability rock will be realised in order to study the air interaction as well as the effects it engenders on the host formation behaviour. The studied rock is the Callovo-Oxfordian claystone ( $\mathrm{COx})$ which is envisaged for deep underground repository of nuclear wastes in France [4].

Before modelling this ventilation experiment, the material transport properties have to be characterised. They mainly depend on the fracturing process and on the hydraulic permeability increase it engenders. Considering the fracturing process, shear strain localisation can be considered as a precursor to fractures. In fact, material rupture is generally preceded by localised deformation in shear band mode [5] that can lead to material damage, microcracks and fractures. With such macroscopic description, the evolution of permeability within the EDZ can be associated to the strain localisation discontinuities with a dependence to the mechanical deformation.

Numerous modelling of the EDZ behaviour have been realised in the past decades. Theses modelling often include separately hydro-mechanical coupling 40 [6, 7], permeability variation [8], flow transfers [9, or strain localisation [10]. For strain localisation approaches, there is a lack of numerical modelling which takes into account these different aspects simultaneously, at large scale, and which reproduce in situ experimental measurements. The coupled and simultaneous reproduction of these phenomena constitutes the objective and originality of the 45 proposed modelling.

In the present study, a particular attention is given to the characterisation of the EDZ and of the flow transfers during gallery excavation and ventilation. It will be investigated with a non-linear finite element method (code Lagamine) for the Callovo-Oxfordian claystone, a low permeability rock exso hibiting a transversely isotropic behaviour. EDZ evidences and the considered large-scale air ventilation experiment are firstly detailed in section 2 . Then, the hydro-mechanical constitutive model is developed in section 3 for an unsaturated 
porous media.

Finally, the gallery excavation and the air ventilation experiment are nu55 merically modelled in the section 4. The first numerical phase is the gallery excavation modelling during which the development of the fractures that compose the EDZ is reproduced by shear banding [10]. Considering the fractured rock as a continuous medium at the macroscale, the intrinsic hydraulic permeability evolution is reproduced through a strain-dependent relation. Succeeding to the excavation, the air ventilation experiment is reproduced in the underground gallery. In this second numerical phase, the exchanges at gallery wall between the claystone and the cavity air are characterised with a non-classical mixed hydraulic boundary condition [11, 12]. Then, the influence of the controlled ventilation on the claystone behaviour is analysed, including a particular

65 focus on the drainage and desaturation kinetics.

\section{Underground drilling and air ventilation}

The material behaviour around underground structures is significantly influenced by the drilling process and by the air-material interaction. On one hand, the drilling leads to the appearance of cracks or fractures concentrated in an

7o Excavation Damaged Zone (EDZ) that develops around galleries. On the other hand, the interaction with air may engender drainage and desaturation. Both of these aspects modify the transport properties of the underground material.

In the context of research on deep underground nuclear waste repository, Underground Research Laboratories (URL) have been constructed in very low 75 permeability media with the objective of characterising the possible host formations and evaluating the feasibility of a safe repository [3]. Because air ventilation is performed during the construction and operational phases of the galleries that compose the underground structures, air ventilation experiments are performed in URL to investigate the interaction with air and its effects on the host material. In the following, we will particularly focus on the behaviour of the Callovo-Oxfordian claystone. In the Meuse/Haute-Marne URL, the French 
national radioactive waste management agency (Andra) performs a large-scale ventilation experiment called Saturation Damaged Zone experiment (SDZ) in an experimental gallery (GED) [9, 13]. This experiment will be studied and 85 numerically reproduced in the following work.

Hereafter, the excavation damaged zone developing around the experimental gallery and the SDZ ventilation experiment are described.

\subsection{Excavation damaged zone}

It has been widely observed that underground drilling leads to stress redis-

90

fractures (macrocracks) around drifts [1]. Thence, an excavation damaged zone expands in the surrounding medium with significant irreversible modifications of hydro-mechanical and geochemical properties due to the fracturing process [2]. These changes inevitably induce major modifications of the material transport 95 and flow characteristics such as the hydraulic permeability [14, 15, 16]. When considering the long-term waste repository and the safety function of the host formation, the EDZ behaviour is a crucial issue because it could constitute a preferential flow path [17]. Modelling the damaged zone and its hydraulic property modifications is therefore important when considering hydraulic transfers around underground drifts.

The EDZ has been carefully investigated in URL through, for instance, fracture measurements, permeability analysis, and flow transfers. For the CallovoOxfordian claystone, induced extension and shear fractures are detected in the proximity of the galleries composing the Andra's URL, with shearing as the principal failure mechanism because of the high in situ stress environment [1].

In the fractured zone, the hydraulic permeability can severely increase up to several orders of magnitude, especially due to the presence of interconnected extensional fractures [18].

Concerning the SDZ ventilation experiment, it is performed in the GED experimental gallery which is oriented parallel to the minor horizontal principal stress. Around this gallery and the SDZ experimental zone, the permeabil- 
ity increase has been highlighted by measurements performed under saturated conditions in boreholes that are drilled in different orientations (Fig. 1] (a)). Moreover, the permeability measurements in the fractured zone are representative of the fracture permeability, not of the permeability of the continuous rock matrix. Three zones can be defined: an undisturbed zone with a permeability lower than $10^{-19} \mathrm{~m}^{2}$ far from the gallery, a slightly disturbed zone with a permeability ranging from $10^{-19} \mathrm{~m}^{2}$ to $10^{-17} \mathrm{~m}^{2}$, and a highly disturbed zone close to the gallery with a permeability higher than $10^{-17} \mathrm{~m}^{2}$ (increase higher than 2 orders of magnitude). The extents of the zones are detailed in Fig. 1 (b) and superposed to the experimental data in Fig. 1 (a). A parallelism between hydraulic measurements and fracture measurements can be evidenced and the permeability zones can then be related to shear and tensile fracture zones (Fig. 1 (b)). The damaged zone shape also differs depending on the induced fracture network which is related to the orientations of the galleries and to the stress state anisotropy [18].

\subsection{Ventilation experiment}

At nuclear waste repository scale, air ventilation is performed in the underground galleries during the excavation and maintenance phases. This ventilation could impact the behaviour of the underground structures by draining the water from the rock. In case of important drainage, it can even lead to rock desaturation, stress modification, as well as modification of the fracturing structure close the the drifts. As a consequence, the damaged zone behaviour could be affected [19].

135 In order to investigate the rock-atmosphere interactions, large-scale ventilation experiments are performed in underground research laboratories. Among them are the Ventilation Experiment (VE) carried out at Mont Terri URL in Switzerland 20] and the Saturation Damaged Zone experiment (SDZ) conducted in Andra's URL [9, 13]. The major objective is to characterise the influence of 140 a controlled ventilation on the hydro-mechanical behaviour of the rock mass and on the hydraulic transfers taking place around the galleries, especially in 
(a)

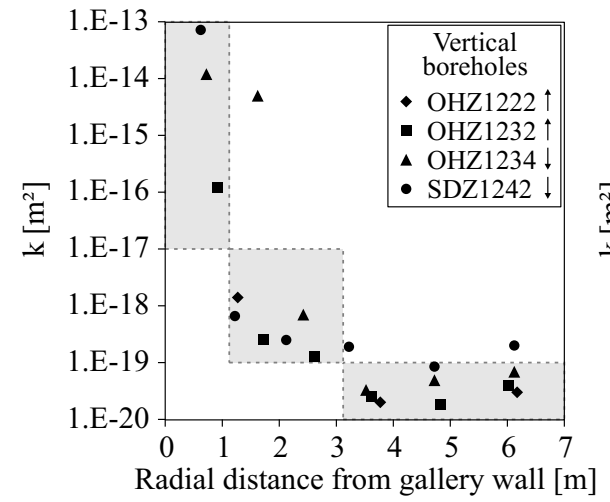

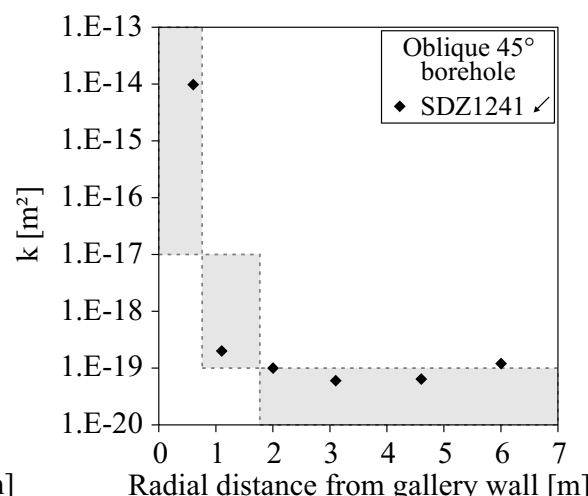

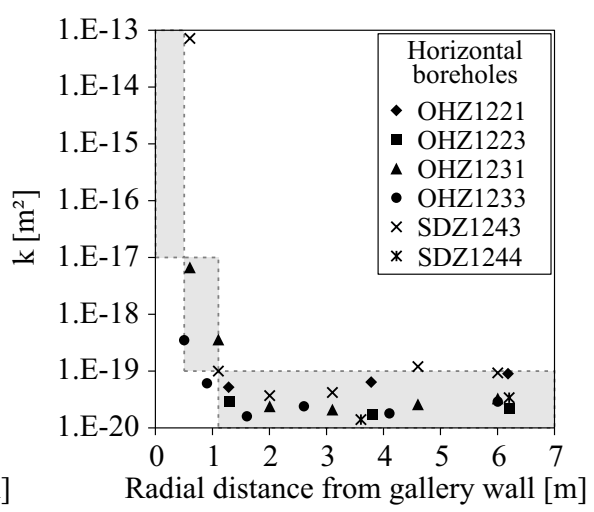

(b)

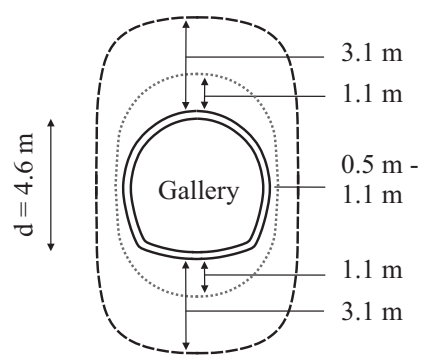

\begin{tabular}{|c|}
\hline Permeability zones \\
-.-. Slightly disturbed \\
$10^{-19}<\mathrm{k}<10^{-17} \mathrm{~m}^{2}$ \\
$\ldots \ldots$. \\
Highly disturbed \\
$\mathrm{k}>10^{-17} \mathrm{~m}^{2}$ \\
\hline$\cdots$
\end{tabular}

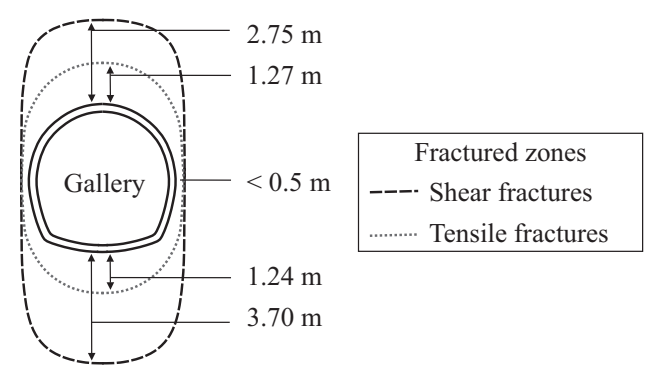

Figure 1: Intrinsic hydraulic permeability around the GED drift and the SDZ experimental zone in Callovo-Oxfordian claystone [18]: (a) evolution along boreholes and (b) extensions of permeability and fracture zones. 
the excavation damaged zone. A particular attention is paid to the material deformation, drainage, and desaturation processes during the tests.

The ventilation experiment we are interested in is the SDZ test which is 145 performed at the end of the GED drift in the Andra's URL (Fig. 2 (a)). An experimental zone is isolated from the rest of the laboratory and is subjected to a controlled ventilation. Different levels of hygrometry are applied in order to highlight the effect of drainage and wetting, or of desaturation and possible resaturation. The experimental zone presented in Fig. 2 (a) is divided in two parts: one with concrete covering and impervious geotextile on the gallery wall, and another without covering where the air-rock exchanges can be directly studied. An airlock is also present to isolate the experimental zone from the rest of the laboratory. The ventilation can be sequenced in different phases (Fig. 2 (b)): (1) the first phase corresponds to the global laboratory ventilation before the airlock closure, (2) once the airlock is closed the ventilation is stopped in the experimental zone and the exchanges with the GED gallery occur through the excavation damaged zone, later a controlled ventilation is imposed with hygrometric conditions of (3) $30 \%$ of relative humidity and $23^{\circ}$ then of (4) $60 \%$ of relative humidity and $22^{\circ}$. The air temperature $T$ and relative humidity $R H$ evolutions are monitored in the experimental zone in different gallery sections. The measurements are illustrated in Fig. 2(b) with the four different ventilation phases.

Several in situ experimental measurements are realised during the test. The pore water pressure evolution inside the rock mass, around the experimental zone without covering, is monitored in different boreholes having different orientations [9]. These boreholes are drilled from the gallery wall some time after its excavation and are instrumented with pore water pressure sensors. The sensors are set up at different depths and can acquire measurements in a range going from 0 to $10 \mathrm{MPa}$. These measurements are illustrated in Fig. 3 The set-up operations require a certain amount of time and the beginning of the measurements starts about 200 days after the excavation of the gallery. Once the measurement starts, a first phase corresponding to the equilibrium of the 


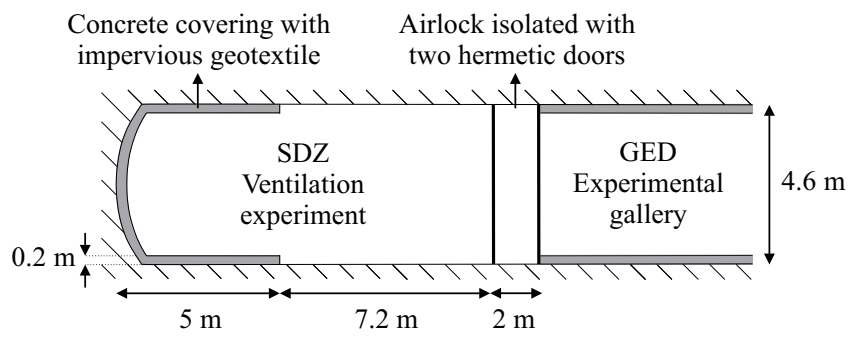

(a)

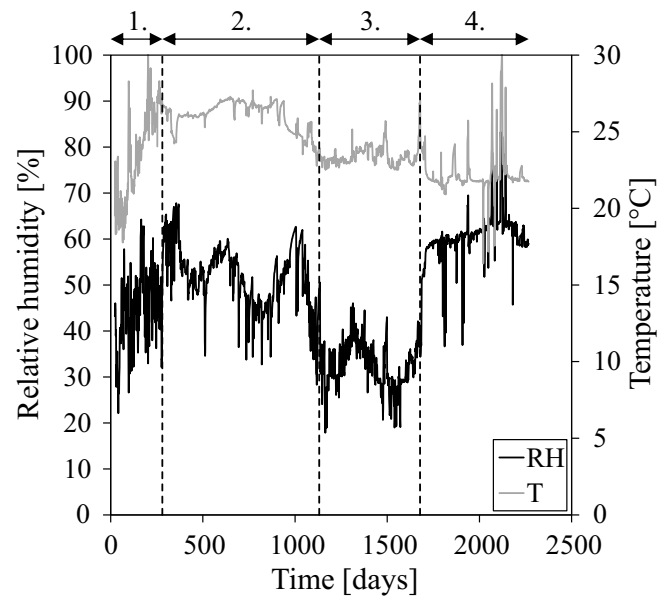

(b)

Figure 2: SDZ experiment: (a) geometry of the experimental zone located at the end of the GED drift in Callovo-Oxfordian claystone [9] and (b) temperature and relative humidity evolution in the experimental zone.

sensors with the rock mass (pressurising of the sensors) is observed. It results in an increase of the pore water pressure in the sensors up to the rock mass pore pressure. Once the equilibrium is reached, the progressive drainage of the rock is monitored with a decrease of the pore water pressure.

One can observe in Fig. 3 that the drainage is not important in the far field, where the pore water pressures are close to the initial rock water pressure. It is more important close to the gallery where the measurements are close to the atmospheric pressure (in a $3 \mathrm{~m}$ ring). In the excavation damaged zone, we can expect that the increase of permeability and the drainage lead to rock desaturation. Unfortunately, the sensors can not acquire negative measurements and can not characterise the desaturation. In the long term, the two controlled ventilation phases (phases (3) and (4) in Fig. 2 (b)) only have a minor effect on the measured pore water pressure. The decrease of the pore water pressure measurements is slightly reduced when the wetting phase with $R H=60 \%$ is applied (phase (4) after 1680 days).

To characterise the desaturation, water content measurements have also been 
performed on core samples coming from horizontal boreholes drilled in the experimental zone without covering. The experimental results are illustrated in Fig. 4. They indicate, firstly, a strong desaturation close to the gallery wall with $3 \% \leq w \leq 5 \%$ that can extend up to $0.5 \mathrm{~m}$ depth, secondly, a moderated desaturation deeper in the rock, and thirdly, a limited desaturation or no desaturation deeper than $2 \mathrm{~m}$ with $6.7 \% \leq w \leq 8.2 \%$ for the saturated claystone. Furthermore, a geological survey of the fractured zone as well as measurements of the gallery convergence are also performed by the Andra after the gallery excavation.

\subsection{Modelling issues}

The observations mentioned here above clearly indicate the need for a modpermeability increase inside the fractures (shear bands) due to strain localisation effect.

The second step is the modelling of the gallery air ventilation. The SDZ experiment in the experimental zone without covering will be reproduced after 215 reproduce the exchanges at gallery wall correctly. The ventilation experiment has already been studied in [9] but only for the uncontrolled ventilation phase (phase (2)), with an EDZ a priori defined in the numerical model (higher in- 


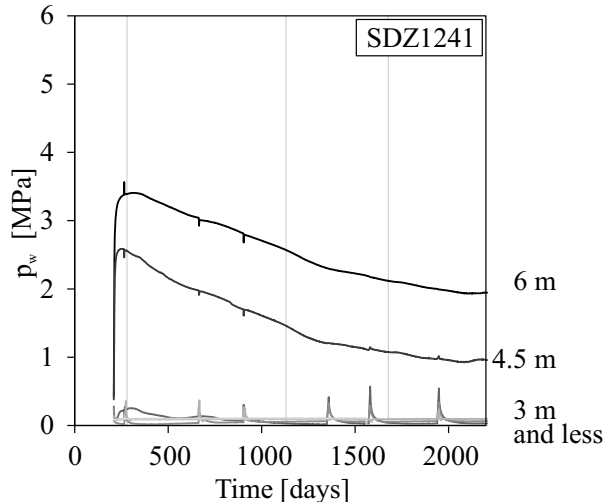

(a)

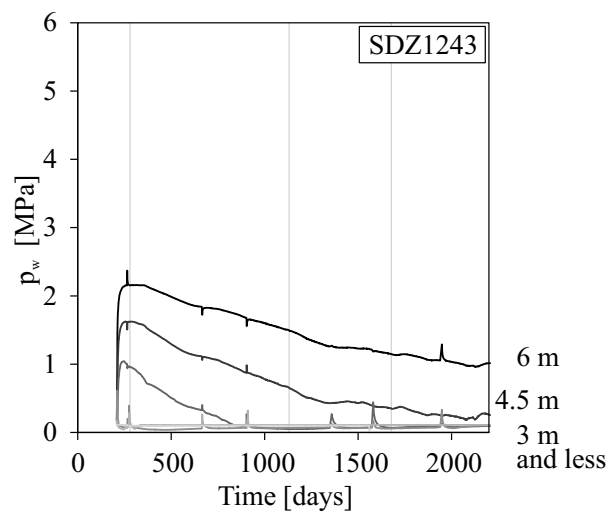

(c)

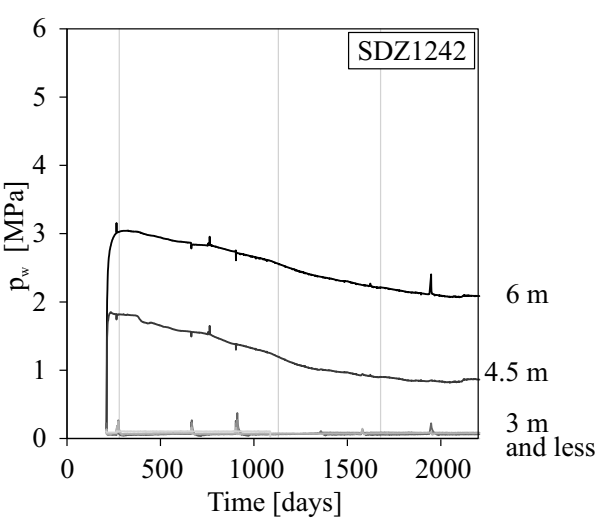

(b)

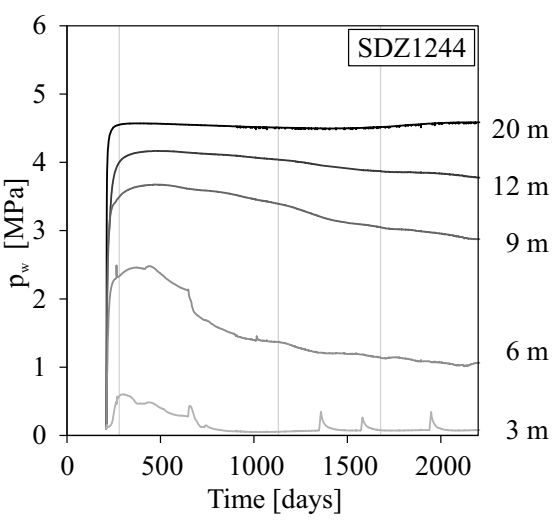

(d)

Figure 3: Pore water pressure evolution in boreholes drilled around the SDZ experimental zone for different distances from gallery wall: (a) oblique at $45^{\circ}$, (b) vertical, and (c,d) horizontal boreholes. 


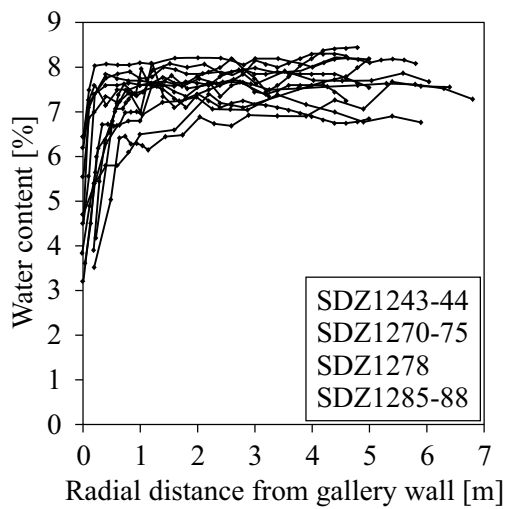

Figure 4: Water content evolution around the SDZ experimental zone in the horizontal direction.

trinsic permeability), without fracture description, and without considering the EDZ desaturation. In the following numerical modelling, these different aspects will be investigated with a more elaborate description of the hydro-mechanical coupling, especially within the EDZ. In fact, the coupling between mechanical deformation, permeability, and hydraulic flow, which was not taken into account in earlier modelling, is indubitably of paramount importance to obtain an adequate representation of the EDZ hydro-mechanical behaviour.

The followed objective is not to develop a complex constitutive model for the Callovo-Oxfordian claystone. It is to investigate if shear banding can be an adequate numerical tool for the reproduction of the EDZ and of the hydraulic transfer at large scale around excavated galleries. The originality of the proposed approach is therefore to represent the EDZ with shear banding and to couple the permeability degradation to strain localisation effects. This type of modelling has not been widely performed at large repository scale with the objective of reproducing in situ measurements. The numerical novelties include also the simultaneous consideration of initial anisotropy, strain localisation effect in microstructure medium, permeability evolution, transfer at gallery wall, and material viscosity. Putting together these various ingredients in finite element method for coupled hydro-mechanical problems at large repository scale 
constitutes an originality of the numerical work.

\section{Constitutive models}

240 grains and pore fluid [21, generally water. The modelling of underground drilling and ventilation therefore requires a hydro-mechanical model describing the constitutive equations of the coupled problem for an unsaturated porous media. Various models can be used to numerically predict the EDZ and the rock behaviours around galleries. Among others, hydro-mechanical damage models can be used to study the EDZ behaviour in unsaturated porous rock, as done in [22] for granite and in 23] for argillite for instance. The modelling of the material behaviour can even include thermal and chemical aspects through complex thermal-hydrological-mechanical-chemical (THMC) models, as detailed in [24], in porous granular rocks can be diverse. It can be related to weak discontinuities (deformation bands) or to strong discontinuities and depends on the type of material and solicitation. A synthesis of the failure modes in granular rock is exposed in [26] and more details on the modelling of deformation bands can be found in the work of Borja and co-workers 27.

The approach considered in the following modelling involves strain localisation in shear bands. For the latter, the appropriate reproduction of shear banding in geomaterials with finite element method requires a regularisation technique. The balance equations are firstly recalled for an enriched model which introduces an enrichment of the continuum kinematics with microstructure effects and an internal length scale [28]. Furthermore, the considered approach aims to evaluate the strain localisation capability to predict the EDZ behaviour with a usual hydro-mechanical model.

The mechanical part is defined by an elasto-viscoplastic model taking into account the transversely isotropic behaviour of the rock in both elastic and plastic behaviours. A viscoplastic mechanism is introduced to improve the long-term 
behaviour of the material and the reproduction of the convergence increase. The hydraulic part of the model defines the water flow in unsaturated porous rock. As mentioned in section 2, the hydraulic flow kinetics around the gallery are conditioned by permeability evolution and air-rock interaction. The modification of the permeability in the damaged zone as well as the fluid transfer at gallery wall must be taken into account.

\subsection{Balance equations}

Strain localisation, generally in shear band mode, is in many cases the precursor of material rupture and failure. In this work, we propose to represent the fractures around galleries with shear strain localisation [29, 30, 31, which requires an appropriate numerical method to avoid mesh dependency. In fact, a pathological problem of mesh dependency is inherent to strain localisation modelling with classical finite element methods [32, 33]. The dependence to the finite element discretisation can be tackled by using a proper regularisation technique. Such method has to introduce an internal length scale in the problem to model the post-localisation behaviour correctly. Two principal categories of enhanced models exist: the first one consists in the enrichment of the constitutive law using gradient plasticity or non-local approaches for instance, the second one consists in the enrichment of the continuum kinematics using microstructure effects. Among the existing methods of this second category, the coupled local second gradient model is used [28]. It consists in a continuum kinematic enrichment with a microscale kinematics characterisation [34, 35] of rotation and strain in addition to the classical macroscale kinematics. The model is largely described in [36, 37, and [10].

For every kinematically admissible virtual displacement and pore water pressure fields, $u_{i}^{*}$ and $p_{w}^{*}$, the balance equations are:

$$
\begin{aligned}
& \int_{\Omega}\left(\sigma_{i j} \frac{\partial u_{i}^{*}}{\partial x_{j}}+\Sigma_{i j k} \frac{\partial v_{i j}^{*}}{\partial x_{k}}\right) d \Omega=\int_{\Gamma_{\sigma}}\left(\bar{t}_{i} u_{i}^{*}+\bar{T}_{i} v_{i k}^{*} n_{k}\right) d \Gamma \\
& \int_{\Omega}\left(\dot{M}_{w} p_{w}^{*}-m_{w, i} \frac{\partial p_{w}^{*}}{\partial x_{i}}\right) d \Omega=\int_{\Omega} Q p_{w}^{*} d \Omega-\int_{\Gamma_{q}} \bar{q} p_{w}^{*} d \Gamma
\end{aligned}
$$


where $a^{*}$ corresponds to the virtual quantity $a, \sigma_{i j}$ is the Cauchy total stress

field, $u_{i}$ is the macroscale displacement field, $v_{i j}=\frac{\partial u_{i}}{\partial x_{j}}$ is the microkinematic gradient field, $\Sigma_{i j k}$ is the double stress, $\Omega$ is the porous material configuration, $\bar{t}_{i}$ and $\bar{T}_{i}$ are the classical external traction force and the additional external 295 double force per unit area acting on $\Gamma_{\sigma}$, a part of the boundary $\Gamma$ of $\Omega, n_{k}$ is the normal unit vector to the boundary. Further, $\dot{M}_{w}$ is the water mass variation, $p_{w}$ is the pore water pressure ( $p_{w}<0$ if suction), $m_{w, i}$ is the water mass flow, $Q$ is a water sink term, and $\bar{q}$ is the input water mass per unit area imposed on the part of the boundary $\Gamma_{q}$. The double stress $\Sigma_{i j k}$ is independent of the pore water pressure but requires an additional constitutive law introducing the internal length scale.

The pore fluid pressure effect on the total stress field $\sigma_{i j}$ is characterised by Biot's definition of effective stress [38] which considers the solid phase compressibility. For unsaturated and anisotropic materials it reads:

$$
\sigma_{i j}=\sigma_{i j}^{\prime}+b_{i j} S_{r, w} p_{w}
$$

where $S_{r, w}$ is the degree of water saturation, $b_{i j}$ is the Biot's tensor, and $\sigma_{i j}^{\prime}$ is the effective stress field $\left(\sigma_{i j}>0\right.$ and $\sigma_{i j}^{\prime}>0$ for compression).

\subsection{Mechanical model}

An elasto-viscoplastic model with transverse isotropy and horizontal isotropic (bedding) planes is considered for the Callovo-Oxfordian claystone. Anisotropic geomaterials often exhibit limited forms of anisotropy such as orthotropy or transverse isotropy, i.e. cross-anisotropy [39]. For these types of anisotropy, the material characteristics are associated to the orthotropic axes [40]. The material properties depend on the material axes as well as on the orientation.

The linear elastic behaviour of the rock is expressed with the classical Hooke's law [41, 42]. The solid grain compressibility is described through the symmetric Biot's tensor [43] which reduces to a diagonal matrix for transverse isotropy. The parameters describing the elastic material behaviour in the directions per315 pendicular $\perp$ and parallel $\|$ to the isotropic planes, i.e. vertical and horizontal 
Table 1: Elastic mechanical parameters 44].

\begin{tabular}{llll}
\hline Symbol & Name & Value & Unit \\
\hline$E_{\|}$ & Parallel Young's modulus & 5000 & $M P a$ \\
$E_{\perp}$ & Perpendicular Young's modulus & 4000 & $M P a$ \\
$G_{\| \perp}$ & Shear modulus & 1630 & $M P a$ \\
$\nu_{\|\|}$ & Poisson's ratio & 0.24 & - \\
$\nu_{\| \perp}$ & Poisson's ratio & 0.33 & - \\
$b_{\|}$ & Parallel Biot's coefficient & 0.60 & - \\
$b_{\perp}$ & Perpendicular Biot's coefficient & 0.64 & - \\
$\rho_{s}$ & Specific mass & 2750 & $\mathrm{~kg} / \mathrm{m}^{3}$ \\
$D$ & Second gradient elastic modulus & 5000 & $\mathrm{~N}$ \\
\hline
\end{tabular}

respectively, are available in the Table 1 for the Callovo-Oxfordian claystone.

The plastic model is an internal friction model with a Van Eekelen yield surface [45] and a non-associated plasticity. The yield surface is defined as:

$$
F \equiv I I_{\hat{\sigma}}-m\left(I_{\sigma^{\prime}}+\frac{3 c}{\tan \varphi_{c}}\right)=0
$$

where $\varphi_{c}$ is the compression friction angle, $c$ is the cohesion, $m$ is a parameter depending on the Lode angle, $I_{\sigma^{\prime}}$ and $I I_{\hat{\sigma}}$ are the first and second stress invariants. The friction angles and the cohesion can undergo an isotropic softening or hardening introduced with hyperbolic functions [46]. For the cohesion, it reads:

$$
c=c_{0}+\frac{\left(c_{f}-c_{0}\right) \hat{\epsilon}_{e q}^{p}}{B_{c}+\hat{\epsilon}_{e q}^{p}}
$$

where $c_{f}$ and $c_{0}$ are the final and initial cohesions, $B_{c}$ is an evolution parameter, and $\hat{\epsilon}_{e q}^{p}$ is the Von Mises' equivalent deviatoric plastic strain. Its rate form reads:

$$
\dot{\hat{\epsilon}}_{e q}^{p}=\sqrt{\frac{2}{3} \dot{\hat{\epsilon}}_{i j}^{p} \dot{\hat{\epsilon}}_{i j}^{p}}
$$

where $\dot{\hat{\epsilon}}_{i j}^{p}=\dot{\epsilon}_{i j}^{p}-\frac{\dot{\epsilon}_{k k}^{p}}{3} \delta_{i j}$ is the deviatoric part of the plastic strain tensor. A similar expression than Eq. 5 is used for the friction angle. 
The anisotropic plastic behaviour is defined for the cohesion by means of a second order microstructure fabric tensor $a_{i j}$. The latter represents the material fabric and describes the spacial distribution of the strength parameter. Besides, the cohesion also depends on the loading direction with regard to the material microstructure orientation [47, 48]. It is given by the following second order expression:

$$
c_{0}=\bar{c}\left(1+A_{i j} l_{i} l_{j}+b_{1}\left(A_{i j} l_{i} l_{j}\right)^{2}\right)
$$

where $b_{1}$ and $\bar{c}$ are constant microstructure parameters, and $A_{i j}$ is a traceless symmetric tensor $\left(A_{i i}=0\right)$ corresponding to the deviatoric part of the microstructure fabric tensor $a_{i j}$ :

$$
\begin{gathered}
A_{i j}=\frac{a_{i j}}{\bar{c}}-\delta_{i j} \\
\bar{c}=\frac{a_{i i}}{3}
\end{gathered}
$$

Furthermore, $l_{i}$ is a generalised unit loading vector corresponding to the stress resultant acting on the material facets [49, 50, 51]:

$$
l_{i}=\sqrt{\frac{\sigma_{i 1}^{\prime 2}+\sigma_{i 2}^{\prime 2}+\sigma_{i 3}^{\prime 2}}{\sigma_{i j}^{\prime} \sigma_{i j}^{\prime}}}
$$

For transversely isotropic materials, the fabric tensor $A_{i j}$ simplifies thanks to the material symmetry. It becomes a diagonal tensor $\left(A_{i j}=0\right.$ for $\left.i \neq j\right)$ which can be defined with only one parameter. The latter is the microstructure fabric tensor component in the isotropic planes $A_{\|\|}$. The expression of Eq. 7 becomes:

$$
c_{0}=\bar{c}\left(1+A_{\|\|}\left(1-3 l_{\|}^{2}\right)+b_{1} A_{\|\|}^{2}\left(1-3 l_{\|}^{2}\right)^{2}\right)
$$

where $l_{\|}$is the component of the generalised unit loading vector $l_{i}$ acting on a facet parallel to the isotropic planes [49, 50, 51].

The final cohesion $c_{f}$ (Eq. 5 also depends on material fabric and loading orientation by considering $c_{f}=\frac{c_{0}}{\xi}$, with $\xi$ being a constant ratio of cohesion softening. All the plastic parameters of the claystone are available in Table 2 
Table 2: Plastic mechanical parameters 44].

\begin{tabular}{llll}
\hline Symbol & Name & Value & Unit \\
\hline $\bar{c}$ & Microstructure-related parameter & 4.1 & $M P a$ \\
$A_{\|\|}$ & Microstructure-related parameter & 0.117 & - \\
$b_{1}$ & Microstructure-related parameter & 14.24 & - \\
$\varphi_{c, 0}$ & Initial compression friction angle & 10 & $\circ$ \\
$\varphi_{c, f}$ & Final compression friction angle & 23 & $\circ$ \\
$\varphi_{e, 0}$ & Initial extension friction angle & 7 & $\circ$ \\
$\varphi_{e, f}$ & Final extension friction angle & 23 & $\circ$ \\
$B_{\varphi}$ & Friction angle hardening coefficient & 0.001 & - \\
$\xi$ & Ratio of cohesion softening & 5 & - \\
$B_{c}$ & Cohesion softening coefficient & 0.003 & - \\
$\psi$ & Dilatancy angle & 0.5 & $\circ$ \\
\hline
\end{tabular}

and the evolution of the anisotropic cohesion with the loading orientation is 325 presented in [44].

It is to mention that two main types of anisotropies exist: inherent (or initial) and induced anisotropies. The inherent anisotropy of the rock is taken into account in the model; however, the induced anisotropy related to the rock fracturing is not addressed. Induced anisotropy is often considered in micro-macro approaches [8] which is not developed. In the present study, the anisotropic formulation of the material cohesion only accounts for the initial anisotropy which does not evolve during the loading. The impact of fracturation on material strength is nevertheless considered by a reduction of the cohesion up to a residual value (softening) but without modification of the fabric tensor $A_{i j}$. Even if it would certainly be of interest to take into account the anisotropy induced by micro-cracking, we have focused on the fracturing effect on the cohesion softening.

The viscoplasticity is introduced by assuming that the plastic strain is composed of a time-independent instantaneous strain $\epsilon_{i j}^{p}$ and of a time-dependent 
Table 3: Viscoplastic mechanical parameters [7.

\begin{tabular}{llll}
\hline Symbol & Name & Value & Unit \\
\hline$R_{c}$ & Uniaxial compressive strength & 21 & $M P a$ \\
$A$ & Internal friction coefficient & 2.62 & - \\
$C_{s}$ & Cohesion coefficient & 0.03 & - \\
$\beta^{v p}$ & Viscoplastic potential parameter & 0.7 & - \\
$g(\theta)$ & Influence of the Lode angle & 1 & - \\
$\alpha_{0}^{v p}$ & Initial threshold for the viscoplastic flow & 0 & - \\
$A_{0}$ & Reference fluidity & 500 & $s^{-1}$ \\
$\zeta$ & Temperature parameter & $63 \times 10^{3}$ & $\mathrm{~J} / \mathrm{mol}$ \\
$n$ & Creep curve shape parameter & 6.6 & - \\
$B^{v p}$ & Viscoplastic hardening function parameter & $5.0 \times 10^{-3}$ & - \\
\hline
\end{tabular}

creep strain $\epsilon_{i j}^{v p}$. This strain is related to the material viscosity and corresponds to a delayed plastic deformation [52]. The time development of deformation can be related to the progressive evolution of the material microstructure or to mechanical properties degradation (damage) that are due to diverse chemical and physical processes [53, 54]. Different processes with different time scales may exist and lead to different viscoplastic mechanisms. Hereafter, a viscoplastic flow mechanism is introduced with the following loading surface $F^{v p}$ controlled by a delayed viscoplastic hardening function $\alpha^{v p}$ :

$$
\begin{gathered}
F^{v p} \equiv \sqrt{3} I I_{\hat{\sigma}}-\alpha^{v p} g(\theta) R_{c} \sqrt{A\left(C_{s}+\frac{I_{\sigma^{\prime}}}{3 R_{c}}\right)}=0 \\
\alpha^{v p}=\alpha_{0}^{v p}+\left(1-\alpha_{0}^{v p}\right) \frac{\epsilon_{e q}^{v p}}{B^{v p}+\epsilon_{e q}^{v p}}
\end{gathered}
$$

where $\epsilon_{e q}^{v p}$ is the equivalent viscoplastic strain. The complete viscoplastic model is detailed in [7, 55] and all the parameters for the Callovo-Oxfordian claystone are detailed in Table 3 .

Similarly to classical media for which a constitutive stress-strain relationship is required, an additional constitutive law has to be defined between the double 
stress $\Sigma_{i j k}$ and the microkinematics for a microstructure medium. The internal length scale is introduced through a second gradient constitutive equation link345 ing the double stress to the micro second gradient $\frac{\partial v_{i j}}{\partial x_{k}}$. The mechanical law is an isotropic linear elastic relationship defined as [56]:

$$
\left[\begin{array}{l}
\tilde{\Sigma}_{111} \\
\tilde{\Sigma}_{112} \\
\tilde{\Sigma}_{121} \\
\tilde{\Sigma}_{122} \\
\tilde{\Sigma}_{211} \\
\tilde{\Sigma}_{212} \\
\tilde{\Sigma}_{221} \\
\tilde{\Sigma}_{222}
\end{array}\right]=D\left[\begin{array}{cccccccc}
1 & 0 & 0 & 0 & 0 & \frac{1}{2} & \frac{1}{2} & 0 \\
0 & \frac{1}{2} & \frac{1}{2} & 0 & -\frac{1}{2} & 0 & 0 & \frac{1}{2} \\
0 & \frac{1}{2} & \frac{1}{2} & 0 & -\frac{1}{2} & 0 & 0 & \frac{1}{2} \\
0 & 0 & 0 & 1 & 0 & -\frac{1}{2} & -\frac{1}{2} & 0 \\
0 & -\frac{1}{2} & -\frac{1}{2} & 0 & 1 & 0 & 0 & 0 \\
\frac{1}{2} & 0 & 0 & -\frac{1}{2} & 0 & \frac{1}{2} & \frac{1}{2} & 0 \\
\frac{1}{2} & 0 & 0 & -\frac{1}{2} & 0 & \frac{1}{2} & \frac{1}{2} & 0 \\
0 & \frac{1}{2} & \frac{1}{2} & 0 & 0 & 0 & 0 & 1
\end{array}\right]\left[\begin{array}{c}
\frac{\partial \dot{v}_{11}}{\partial x_{1}} \\
\frac{\partial \dot{v}_{11}}{\partial x_{2}} \\
\frac{\partial \dot{v}_{12}}{\partial x_{1}} \\
\frac{\partial \dot{v}_{12}}{\partial x_{2}} \\
\frac{\partial \dot{v}_{21}}{\partial x_{1}} \\
\frac{\partial \dot{v}_{21}}{\partial x_{2}} \\
\frac{\partial \dot{v}_{22}}{\partial x_{1}} \\
\frac{\partial \dot{v}_{22}}{\partial x_{2}}
\end{array}\right]
$$

where $\tilde{\Sigma}_{i j k}$ is the Jaumann double stress rate and $\frac{\partial \dot{v}_{i j}}{\partial x_{k}}$ is the micro second gradient rate. The constitutive elastic parameter $D$ (Table 1 represents the physical microstructure and is associated to an internal length relevant for the localisation solutions obtained with the second gradient method is illustrated in [37.

As already mentioned, microstructure media are a category of media for which the deformation effects at the microscopic scale are taken into account in 355 the global balance equations. These microstructure effects are introduced by the second gradient law which constitutive parameter depends on the microstructure. However, in the following modelling, this parameter is assumed constant during the numerical simulation. Further developments would be pertinent to take into account a coupling between plasticity, damage, and the parameter of 360 the second gradient law. Such coupling has already been realised for concrete applications [58] but is not considered hereafter. 
Table 4: Hydraulic parameters [60, 9].

\begin{tabular}{llll}
\hline Symbol & Name & Value & Unit \\
\hline$k_{\|\| l, 0}$ & Initial parallel intrinsic water permeability & $4 \times 10^{-20}$ & $\mathrm{~m}^{2}$ \\
$k_{\perp \perp, 0}$ & Initial perpendicular intrinsic water permeability & $1.33 \times 10^{-20}$ & $\mathrm{~m}^{2}$ \\
$\Phi$ & Porosity & 0.173 & - \\
$M$ & van Genuchten coefficient & 0.33 & - \\
$P_{r}$ & Air entry pressure & 15 & $\mathrm{MPa}$ \\
$S_{\text {max }}$ & Maximum degree of water saturation & 1 & - \\
$S_{\text {res }}$ & Residual degree of water saturation & 0.01 & - \\
$\alpha$ & Vapour mass transfer coefficient & $10^{-3}$ & $\mathrm{~m} / \mathrm{s}$ \\
$K^{\text {pen }}$ & Seepage penalty coefficient & $10^{-10}$ & $\mathrm{~s}^{3} / \mathrm{kg}$ \\
\hline
\end{tabular}

\subsection{Hydraulic model}

The liquid phase transfer (advection) in porous media is defined by Darcy's flow:

$$
m_{w, i}=-\rho_{w} \frac{k_{i j} k_{r, w}}{\mu_{w}} \frac{\partial p_{w}}{\partial x_{j}}
$$

where $m_{w, i}$ is the water mass flow, $k_{r, w}$ is the relative water permeability, $k_{i j}$ is the anisotropic intrinsic (saturated) water permeability tensor, $\rho_{w}$ is 365 the water density, $\rho_{w}=1000 \mathrm{~kg} / \mathrm{m}^{3}$, and $\mu_{w}$ is the water dynamic viscosity, $\mu_{w}=0.001 \mathrm{~Pa} \mathrm{~s}$. The unsaturated behaviour of the material is reproduced by defining a retention curve from van Genuchten's model and a relative water permeability curve from Mualem - van Genuchten's model [59]. The claystone parameters for these models are available in Table 4.

\subsubsection{Intrinsic hydraulic permeability evolution}

Modelling the hydraulic property evolution and inhomogeneity inside the damaged zone is a crucial issue when considering rock drainage and desaturation. Different approaches exist to take into account the influence of cracks and fractures on hydraulic permeability, depending on their descriptions. In fact, 
the fracturing process instigates discontinuities in a material that can be represented theoretically and numerically by various methods. Two mains categories exist: the continuous and discontinuous (discrete) descriptions of the fractures. The continuous description includes deformation, material damage, and strain localisation; while the discrete description actually represents the cracks. Consequently, the permeability evolution law must be related to the chosen cracks description.

For porous materials, a first well-known approach is the Kozeny-Carman relationship that links the intrinsic hydraulic permeability to the soil porosity 61. However, it is commonly assumed in soil mechanics that this relation is 385 approximately valid for sands but not for clay materials; thus, this relation is not commonly used [61]. Other relations linked to the porosity can be studied, for instance a power evolution of intrinsic permeability with porosity is considered for a gallery excavation in 62. The numerical results indicate that the permeability increase can be reproduced around a gallery. Nevertheless, using a variation with the porosity highlights volumetric deformation effects which remain low for slightly dilatant material such as the studied claystone.

Another possible approach is to consider rock damage and the appearance of microcracks in the rock with coupling between microcracking and permeability [22, 63]. In fact, damage in rock is related to the formation of a network of cracks that can constitute preferential flow paths in the material. The damage by microcracking process (initiation, growth, accumulation, propagation, and coalescence of microcracks) is represented in damage models by the degradation of the material characteristics, either mechanical or hydraulic. Different damage models exist in the context of continuum damage mechanics from purely macroscopic (phenomenological) and continuous approaches [64, 65, 66] to multi-scale (micromechanical) approaches. For instance, models with multiscale and homogenisation approaches of permeability evolution are developed [67, 68] and applied to the excavation damaged zone in rock [8]. The macroscopic homogenised permeability of a heterogeneous material depends on the 405 permeability of the solid matrix as well as on the permeability and shape of the 
microcracks. Numerical results indicate that a significant permeability increase of several orders of magnitude can be obtained in the excavation damaged zones developing around boreholes. Nonetheless, rock damage is not incorporated in the present study and another type of permeability evolution must be computed.

Microcracking process can lead to the coalescence of microcracks. When this happens, the distributed damage becomes localised which engenders strain localisation and later the onset of interconnected fractures. The latter are also called macrocracks and can be of different types such as tensile or shear. For tensile fractures, it can be assumed that the fracture opening leads to a permeability increase in the fracture direction (anisotropic permeability increase) and therefore that the traction is an important factor leading to preferential flow paths. The permeability evolution can be described as a function of the crack normal stress or as a function of the crack aperture [69] and density. Traditionally, the hydraulic flows in rock joints have been expressed with a cubic law under the 420 parallel plates approach [70. Macroscopic [71] and, more recently, multi-scale [67] approaches have also been used. For macroscopic approaches, the evolution of fracture opening can be linked to the tensile strain in the normal direction of the crack [72, 73, 74]. Such method has been applied to underground borehole drilling for an indurated clay [75] with anisotropic permeability and which pre425 vailing mechanism of fracture in the excavation damaged zone is extension [76]. The numerical results indicate that the size of the EDZ, based on the predicted permeability increase, is overestimated if the tensile strain includes both plastic and elastic parts. However, considering only the plastic zone underestimates the size of the EDZ [75, 2]; thus, it seems necessary to consider the plastic zone and a part of the elastic one to better reproduce the EDZ extent.

For the Callovo-Oxfordian claystone, shearing is the principal failure mechanism around the galleries at the underground laboratory level because of the high in situ stress [18. In this study, the shear fractures are represented at macroscale by shear strain localisation in band mode; thus, the permeability 435 evolution can be linked to the deformation. In fact, in our approach the strain is amplified in the shear bands by the localisation process and the increase of 
permeability in the fractured zone can be reproduced by linking the hydraulic intrinsic permeability to the strain. This type of hydro-mechanical coupling takes into account the effects of strain localisation and will engender a permeability 440 increase that is more pronounced inside the shear bands.

Considering the fractured rock at the macroscale as a continuous medium, a strain-dependent isotropic evolution of the hydraulic permeability tensor (empirical relationship) is taken into account based on a power (cubic) formulation 62]:

$$
k_{i j}=k_{i j, 0}\left(1+\beta\langle\gamma\rangle^{3}\right)
$$

where $k_{i j, 0}$ is the initial intrinsic water permeability tensor, $\beta$ is an evolution parameter, \langle\rangle are the Macaulay brackets, and $\gamma$ is a deformation parameter. Exponential and power laws as Eq. 16 are often used to describe permeability evolution and water transfer in porous media [77, 61, 78, 74]. The validity and

445 calibration of this empirical relationship will be evaluated in the numerical modelling by envisaging different expressions of $\gamma$ and by using in situ experimental measurements.

As for the cohesion anisotropy, the initial anisotropy of permeability is taken into account but not the anisotropy induced by micro-cracking. The evolution 450 which is considered for permeability is isotropic and conserves the initial directions of anisotropy as well as the permeability ratio. Nonetheless, it is known that the principal directions of anisotropy in the excavation damaged zone do not correspond to the principal directions of the initial anisotropy [15]. During the excavation, the micro-cracking influences the permeability and induces 455 a modification of the permeability tensor. The permeability increase is indeed more important in the longitudinal direction of the cracks and fractures which engenders an anisotropic modification of the permeability (induced anisotropy).

Nevertheless, during the creation of macro-cracks, the rock permeability increases of several orders of magnitude. In that case, the important aspect is mainly to correctly reproduce the variation of permeability between the fractured zones (localised zones) and the undamaged rock. The fact that the initial 
directions of anisotropy are kept can be justified by the important increase of permeability in the damaged zone with regard to the low ratio of anisotropy. In fact, the water transfers are principally affected by the important increase 465 of permeability in the excavation damaged zone. The contrast of permeability between the intact rock and the fractured zone is of such importance that the anisotropy of the fractured zone does not have an important impact on the water transfer around the gallery and in the rock formation. Consequently, the principal directions of anisotropy should not influence the numerical results significantly.

As mentioned previously, considering the plastic deformation and a restricted part of the elastic deformation may allow to better reproduce the EDZ extent. To do so, if $\gamma$ is a parameter which represents the total strain, the Eq. 16] can be adapted as follows:

$$
k_{i j}=k_{i j, 0}\left(1+\beta\left\langle Y I-Y I^{t h r}\right\rangle \gamma^{3}\right)
$$

where $Y I$ is the yield index and $Y I^{t h r}$ is a threshold value below which the intrinsic permeability variation is not considered. The yield index corresponds to the reduced second deviatoric stress invariant:

$$
Y I=\frac{I I_{\hat{\sigma}}}{I I_{\hat{\sigma}}^{p}}
$$

where $I I_{\hat{\sigma}}^{p}$ is the second deviatoric stress invariant value at plastic state (on the yield surface) for an identical value of $I_{\sigma^{\prime}}$ (current value). The material current state is therefore elastic for $Y I<1$ and plastic for $Y I=1$.

Following Eqs. 16 and 17 the intrinsic permeability could decrease if the deformation or the yield index decreases by elastic unloading outside the shear bands. Such phenomenon could be related to fracture closure or to material sealing / healing but it is not treated in the present study. Thus, to avoid permeability decrease, the permeability is, for every computation step, the maximal value between the current and the last computed permeability $k_{i j}^{-\Delta t}$ :

$$
k_{i j}=\max \left(k_{i j}^{-\Delta t}, k_{i j}\right)
$$


Furthermore, new numerical developments are necessary to use the perme475 ability relationships in numerical simulations. The developments mainly consist in implementing the different models in a finite element code, which implies to modify the stiffness matrix of the finite elements. These numerical developments require to develop the finite element formulation of the coupled local second gradient model for microstructure media [79].

\subsubsection{Hydraulic boundary condition}

The air-rock interaction is another crucial issue that conditions the drainage kinetics in the rock formation. Experimental measurements indicate that pore water pressure and water content in the rock decrease progressively during the excavation and the ventilation. In the long term, a thermodynamic equilibrium

485 is reached between the gallery wall rock and the gallery air. These progressive drainage and desaturation seem to imply that the hydraulic transfer between the air and the rock is also progressive and that an instantaneous equilibrium between the air and the rock may not be assumed beforehand. Thus, a boundary condition at gallery wall which takes into account this progressive equilibrium should be used.

The exchanges between the cavity and the rock are modelled with a nonclassical hydraulic boundary condition at gallery wall [11, 9]. This condition implies that two modes of exchange can occur at the gallery wall of ventilated cavities [12]: water vapour and liquid water exchanges. The total water flow corresponds to the sum of the two flows (Fig. 5):

$$
\bar{q}=\bar{S}+\bar{E}
$$

where $\bar{S}$ and $\bar{E}$ are the seepage flow (liquid water) and the evaporation flow (water vapour), respectively. The expression of the hydraulic boundary condition for $\bar{q}$ is taken into account in the water mass balance equation (Eq. 2). This type of mixed condition has not been used for large-scale modelling of 495 gallery ventilation with a strain localisation approach. Using it constitutes an originality of the modelling. 
The vapour exchange mode between a porous media and the air is based on desaturation kinetics at the interface. It can be considered that the exchanges occur in a boundary layer existing on the material porous surface [12 and that they are not instantaneous. The boundary layer controls the exchanges and the external conditions are considered in the layer through a vapour mass transfer coefficient $\alpha$. The exchange is therefore expressed as a function of this coefficient and of a transfer potential. Among different formulations proposed in the literature, the difference between the vapour density in the rock $\rho_{v}^{r}$ and in the cavity air $\rho_{v}^{c a v}$ is considered [80]:

$$
\bar{E}=\alpha\left(\rho_{v}^{r}-\rho_{v}^{c a v}\right)
$$

The transfer coefficient involved in this expression depends on the external drying conditions and can be determined from drying flux curves deduced from laboratory drying experiments [81. Moreover, the water vapour is only taken into consideration in the hydraulic boundary condition. No water vapour is considered in the clayey rock. The water vapour exchange is included in the total water flow at gallery wall which affects the pore water pressure in the rock by Eq. 2 ,

The liquid exchange at gallery wall is an unilateral seepage flow directed towards the gallery that only occurs when the material porous surface is fully saturated. That is to say that a seepage flow exists when the pore water pressure in the rock at gallery wall exceeds the water pressure in the cavity, $p_{w}^{r} \geq p_{w}^{c a v}$, and exceeds the atmospheric pressure, $p_{w}^{r} \geq p_{a t m}$. This flow is introduced by an unilateral boundary condition (Signorini's type) on the pore water pressure through a ramp function:

$$
\begin{cases}\bar{S}=K^{\text {pen }}\left(p_{w}^{r}-p_{a t m}\right)^{2} & \text { if } p_{w}^{r} \geq p_{w}^{c a v} \text { and } p_{w}^{r} \geq p_{\text {atm }} \\ \bar{S}=0 & \text { if } p_{w}^{r}<p_{w}^{c a v} \text { or } p_{w}^{r}<p_{\text {atm }}\end{cases}
$$

where $K^{p e n}$ is a numerical seepage penalty coefficient (Table 44. 


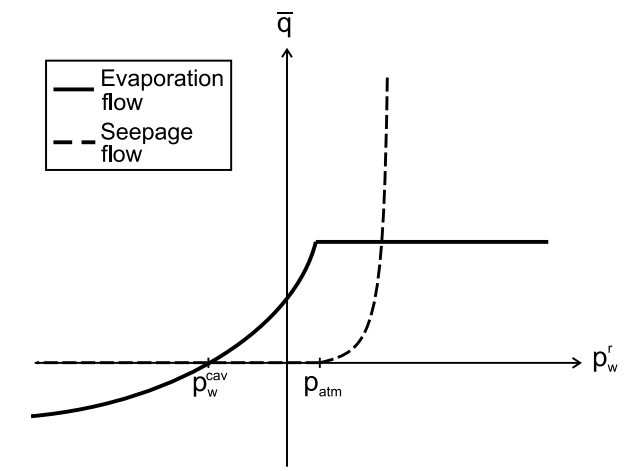

Figure 5: Evaporation and seepage flows at gallery wall for a constant air ventilation [11.

\section{Numerical simulations}

As mentioned previously (section 2), when considering deep underground repository of nuclear waste, there is a need for a more accurate modelling of the EDZ and of the gallery air ventilation effect on the flow transfers taking place around the galleries. Therefore, a hydro-mechanical modelling of gallery

515 strain state.

\subsection{Numerical model}

The considered rock is the Callovo-Oxfordian claystone which is a transversely isotropic material with horizontal bedding planes and an initial anisotropic stress state. For a gallery oriented along the minor horizontal principal stress, the initial stress state and pore water pressure are:

$$
\sigma_{x, 0}=15.6 \mathrm{MPa}
$$




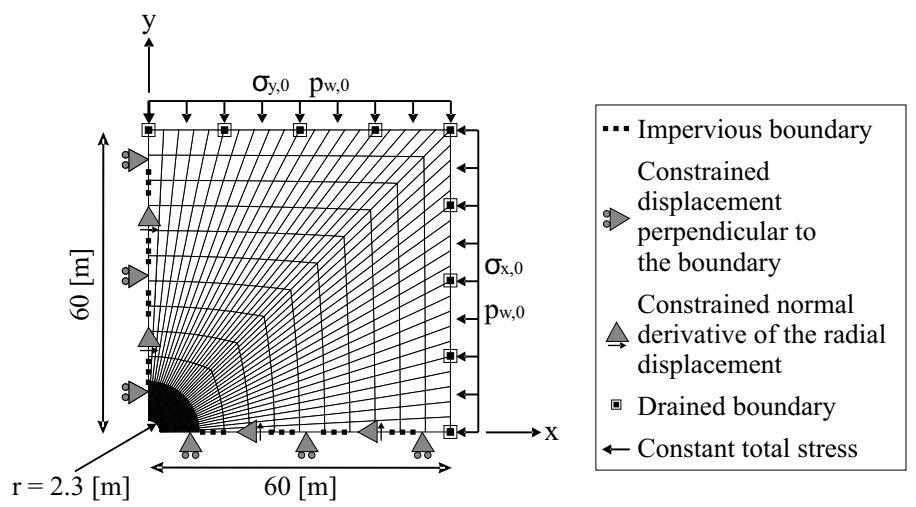

Figure 6: Numerical model and boundary conditions.

$$
\begin{gathered}
\sigma_{y, 0}=\sigma_{z, 0}=12 \mathrm{MPa} \\
p_{w, 0}=4.5 \mathrm{MPa}
\end{gathered}
$$

where $p_{w, 0}$ is the initial pore water pressure and $\sigma_{x, 0}, \sigma_{y, 0}, \sigma_{z, 0}$ are the initial total stresses.

520

The modelling considers the SDZ experimental zone without covering and only one gallery quarter for symmetry reason. The mesh geometry of the 2.3 $\mathrm{m}$ radius gallery is illustrated in Fig. 6 with a discretisation involving 2520 elements and 9802 nodes. To establish the symmetry, the symmetry $\mathrm{x}$ and $\mathrm{y}-$ axes are considered as impervious (no water flow) and the normal displacement

525 as well as the normal derivative of the radial displacement cancel along these axes [10]. At the mesh external boundaries, the normal total stress and the pore water pressure are imposed constant.

\subsection{Excavation and permeability evolution}

As a first step, the drilling process and the EDZ development are modelled. During the excavation, the major objectives are to characterise the development of fractures induced by rock deconfinement and the modification of the hydraulic properties. The fractures are represented with shear banding and the permeability evolution is addressed with a strain-dependent relation. 


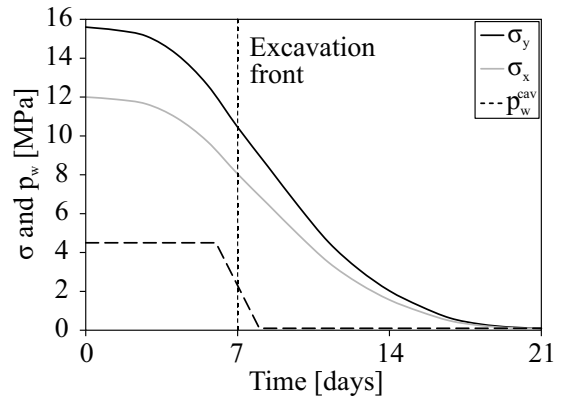

Figure 7: Deconfinement curves for stresses 82 and pore water pressure during gallery excavation.

\subsubsection{Gallery excavation} [82] and decreasing stresses at gallery wall with the excavation front crossing the studied section after one week (Fig. 7). The pore water pressure in the gallery is assumed to decrease rapidly to one atmospheric pressure when the excavation front crosses the studied section. It is assumed that the gallery air remains fully that the air relative humidity is of $100 \%$ and the water pressure in the cavity corresponds to the atmospheric pressure (Fig. 7).

The numerical results in Fig. 8 (a) and (b) present the shear strain localisation bands around the gallery at the end of drilling in terms of plastic zone, represented by the plastic loading integration points, and of Von Mises' equivalent deviatoric total strain:

$$
\hat{\epsilon}_{e q}=\sqrt{\frac{2}{3} \hat{\epsilon}_{i j} \hat{\epsilon}_{i j}}
$$

where $\hat{\epsilon}_{i j}=\epsilon_{i j}-\frac{\epsilon_{k k}}{3} \delta_{i j}$ is the deviatoric part of the strain tensor. During the drilling the deformation and the plastic zone develop firstly in a diffuse manner 545 around the gallery. Then, before the end of the excavation, strain localisation appears in the vicinity of the gallery with the material under plastic loading in the shear bands (concentration of plastic strain) and an elastic unloading in the outer material. The onset of strain localisation is due to the anisotropy 


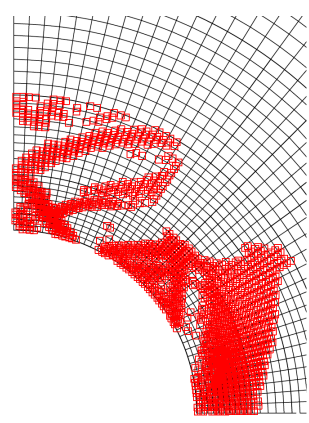

(a)

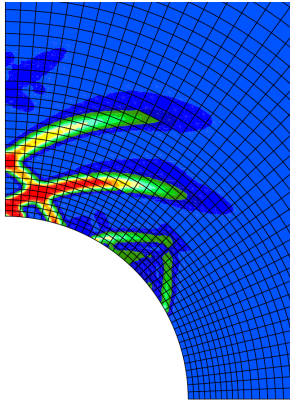

(b)
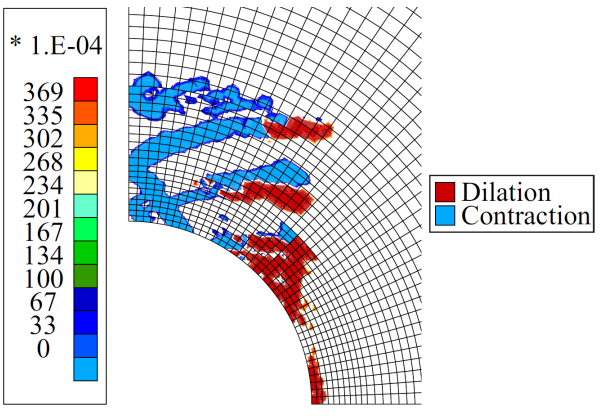

(c)

Figure 8: Localisation zone at the end of excavation: (a) plasticity, (b) equivalent deviatoric strain, and (c) shear band type.

of the material as well as of the initial stress state [10, 44]. Furthermore, the plastic zone extent is more important in the vertical direction as observed in experimental measurements of fractures around the GED gallery (Fig. 1 (b)).

The nature of a shear band depends on different factors as the material characteristics and the loading. Even if the localisation band is called a shear band, it does not automatically deform in pure shearing [83]. For instance, a shearing with dilatancy is generally observed in the shear bands for most geomaterials. Compaction and dilation bands in pure closing and opening also exist for other materials and failure modes. The type of localisation band can be described thanks to the Rice bifurcation criterion and to an additional velocity gradient field of the shear band [84, 85]. The latter characterises the discontinuity of the deformation between the band and the outer material. The discontinuity band nature is defined by a parameter $S$ according to the Table 5 . The type of deformation band for the localised solution is illustrated in Fig. 8 (c) with $-0.62<S<0.96$ inside the shear bands. One can observe that the different bands are in contractive or dilative mode depending on their orientations. They are globally contractive above (and below) the gallery and dilative on the gallery sides. 


\begin{tabular}{ll} 
Table 5: Characterisation of the deformation band type \\
\hline Parameter $S$ value & Band mode \\
\hline-1 & Pure closing \\
]$-1 ; 0[$ & Contractive shearing \\
0 & Pure shear \\
$10 ; 1[$ & Dilative shearing \\
1 & Pure opening \\
\hline
\end{tabular}

\subsubsection{Intrinsic permeability evolution}

The evolution of the intrinsic hydraulic permeability is firstly reproduced with Eq. 16. The evolution parameters for the permeability are calibrated of permeability around the GED gallery (Fig. 1). Different expressions of the deformation parameter $\gamma$ are considered hereafter. For those different expressions, the permeability tensor evolutions are illustrated in Fig. 9 at the end of the excavation, along the symmetry axes and a $45^{\circ}$ inclined direction (vertical, the end of excavation because the main part of the material deformation around a gallery appears during the excavation.

Firstly, the volumetric deformation is used: $\gamma=\epsilon_{v}=\frac{\epsilon_{i i}}{3}$. The results in Fig. 9 (a) are detailed for $\beta=1 \times 10^{14}$. One can observe that the permeability increases of several orders of magnitude around the gallery, especially in the shear bands where the deformation is concentrated. In the horizontal direction, no shear bands are crossed by the x-axis (Fig. 8); then, the increase remains quite diffuse and expands too deeply in the rock formation, in comparison with the experimental data of Fig. 1. As already mentioned, the volumetric deformation remains low for a slightly dilatant material and an important value of $\beta$ has been used to reproduce a permeability increase of several orders of magnitude.

Secondly, to emphasize shear strain effect, the deformation parameter can be taken as equal to the equivalent deviatoric strain (Eq. 23): $\gamma=\hat{\epsilon}_{\text {eq }}$. The 
results for $\beta=1 \times 10^{10}$ in Fig. 9 (b) show a more important increase of the permeability in the shear bands but it increases too deeply in the rock in all directions.

Thirdly, to consider only the plastic deformation in the permeability evolution, $\gamma$ in Eq. 16 can be taken as the equivalent deviatoric plastic strain (Eq. 60: $\gamma=\hat{\epsilon}_{e q}^{p}$. The results for $\beta=1 \times 10^{10}$ are illustrated in Fig. 9 (c). The expand of the permeability increase is satisfactory in the vertical and the oblique directions but it does not increase sufficiently in the horizontal direction in comparison to the experimental measurements of Fig. 1 (a). This would lead to an underestimation of the drainage in that direction. Moreover, if the permeability increase is too much concentrated inside the shear bands then the EDZ does not expand sufficiently. The drainage in the claystone would consequently be underestimated because the rock mass outside the shear bands is not be affected 62 .

An appropriate solution may be an intermediate case between considering all the deformation and only the plastic strain. To consider the plastic strain and a part of the elastic strain, the Eq. 17 is used with the equivalent deviatoric strain $\gamma=\hat{\epsilon}_{e q}$, leading to:

$$
k_{i j}=k_{i j, 0}\left(1+\beta\left\langle Y I-Y I^{t h r}\right\rangle \hat{\epsilon}_{e q}^{3}\right)
$$

The results for $\beta=1 \times 10^{10}$ and $Y I^{t h r}=0.95$ illustrated in Fig. 9 (d) show a permeability increase in a quite good agreement with the experimental measurements for all the directions (Fig. 1). The permeability evolution during the excavation and the comparison to experimental data are illustrated in Fig. 10 (a-c) where a good match is observed. In the far field, the permeability corresponds to the undamaged rock and is well captured in the modelling. In the near field, the permeability corresponds to the fractured rock (EDZ). It is to mention that, for fractured rock, two permeabilities have to be distinguished: the continuous rock matrix permeability and the fracture permeability. In the fractured zone, the permeability measurements are representative of the fracture permeability. In our approach, specific peaks of intrinsic permeability are ob- 


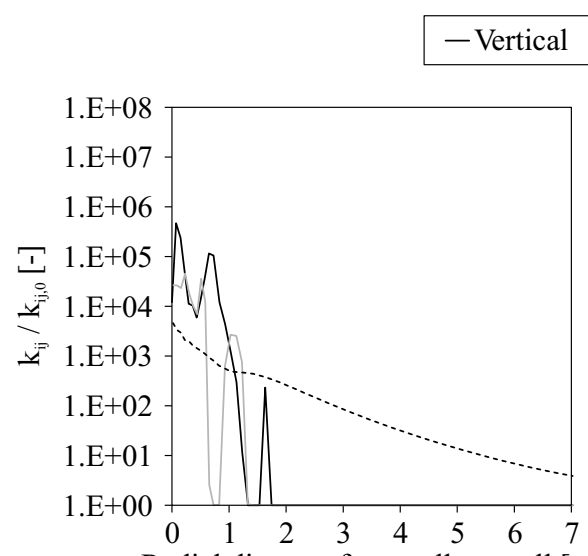

Radial distance from gallery wall $[\mathrm{m}]$

(a)

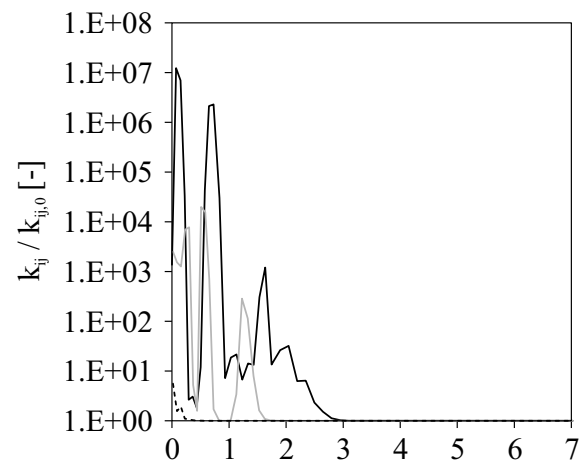

Radial distance from gallery wall [m]

(c)
Oblique -.- Horizontal

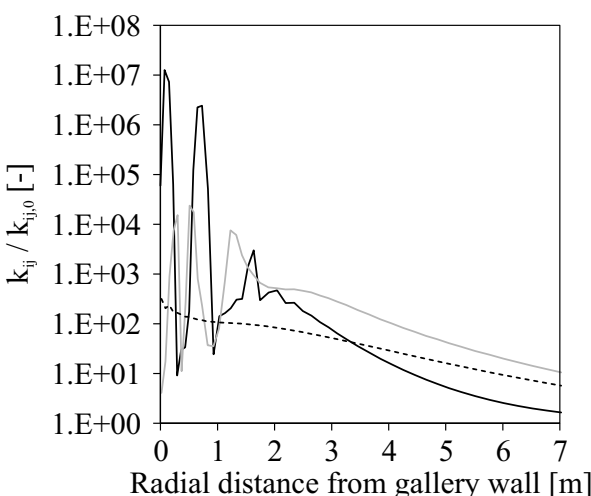

(b)

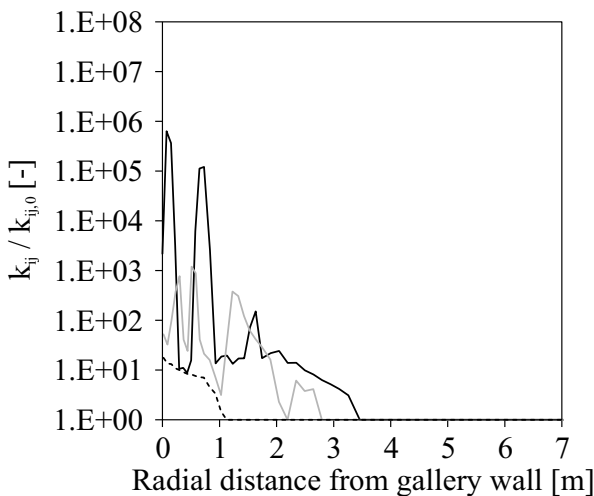

(d)

Figure 9: Intrinsic permeability at the end of excavation for permeability evolution with: (a) volumetric deformation, (b) deviatoric strain, (c) deviatoric plastic strain, and (d) deviatoric strain with yield index threshold. 
tained in the shear bands. This strong permeability increase is of several orders of magnitude which corresponds to experimental measurements. The evolution parameters for the permeability have been calibrated to reproduce this increase.

The numerical results indicate that plastic strain and a limited part of the elastic strain allow a good reproduction of the EDZ extent. The relations of Eq. 24 and 19 with $\beta=1 \times 10^{10}$ and $Y I^{\text {thr }}=0.95$ will consequently be kept for the following modelling. For this permeability evolution, the permeability distribution of the ratio $k_{i j} / k_{i j, 0}$ around the gallery is represented at the end of excavation in Fig. 10 (d) (logarithmic scale). An increase of at least 2 orders of magnitude inside the shear bands is obtained.

Furthermore, it can be observe in in Fig. 10 that, even if the peaks of permeability increase are representative of the fracture permeability, their positions do not exactly correspond to the in situ measurements. In fact, the peak positions are related to the shear band positions which are not controlled in a regularised calculation; only the internal length of the shear bands (i.e. the width of the strain localisation band) is controlled. The uniqueness of the solution in a regularised post-peak calculation is not restored. It implies that the position of the shear bands can not be imposed. As detailed in the following results (Figs. 12 13 , and 15, the chosen set of hydro-mechanical parameters allows to obtain a satisfactory numerical solution regarding the hydraulic and mechanical in situ measurements.

For the Callovo-Oxfordian claystone, the proposed calibration can be used for other galleries having other orientations. The proposed permeability evolution can also be applied to other clay materials with other parameter calibrations. The approach highlights mainly which type of formulation is valid for permeability modification in clay materials. More particularly, it indicates 640 which mechanical components (evolution parameters) can be used in an empirical formulation to reproduce the permeability evolution. 


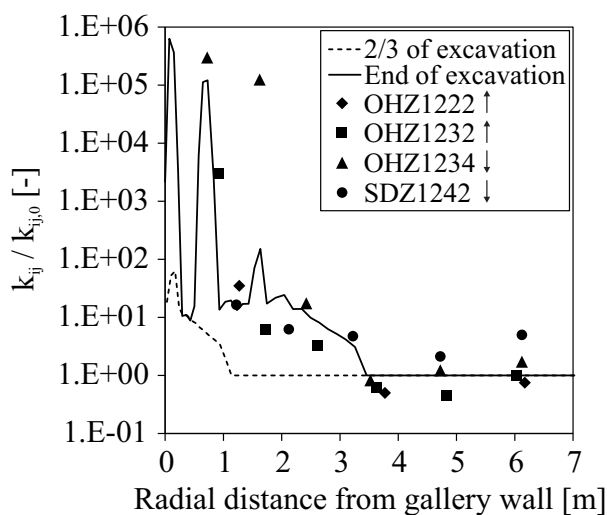

(a)

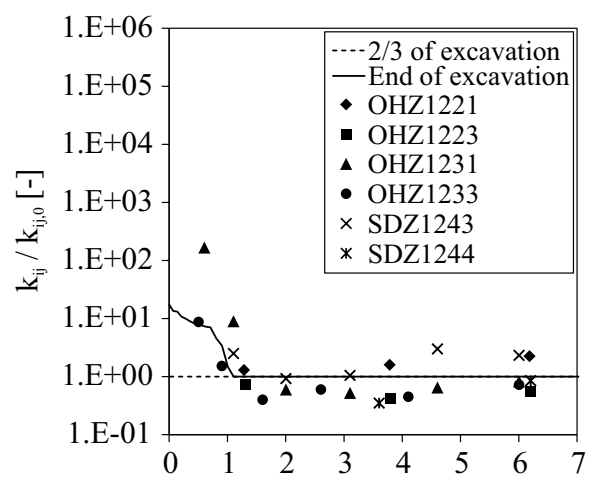

Radial distance from gallery wall $[\mathrm{m}]$

(c)

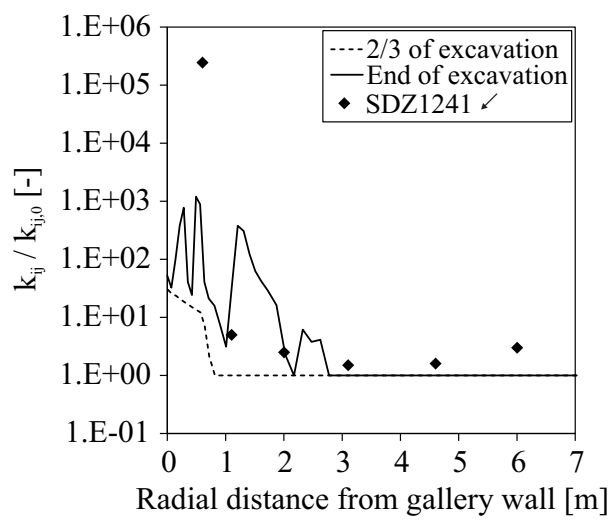

(b)

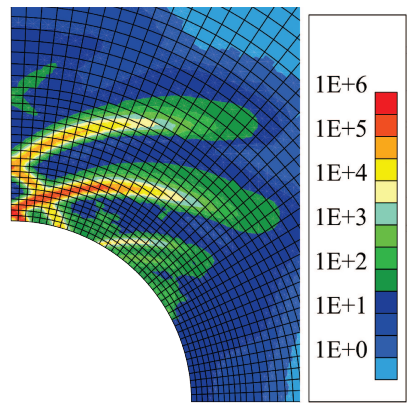

(d)

Figure 10: Intrinsic permeability ratio $k_{i j} / k_{i j, 0}$ : evolution and comparison to experimental data [18 along (a) vertical, (b) oblique at $45^{\circ}$, and (c) horizontal cross-sections; and (d) distribution of the ratio at the end of excavation. 


\subsection{Ventilation and air-rock interaction}

The second part of the numerical modelling consists in applying, after the excavation, an air ventilation in the underground gallery that corresponds to the SDZ ventilation experiment. In previous modelling of this experiment [9], the EDZ was a priori defined in the numerical model with a higher intrinsic permeability than the undisturbed host rock and without description of the fractures. Now, the fracture description as well as the permeability evolution and inhomogeneity in the EDZ have been taken into account. The following challenge is to analyse whether the introduced hydro-mechanical coupling and EDZ description allow to reproduce the drainage and desaturation provoked in the surrounding media by the air ventilation. The principal objectives of the SDZ test modelling are to characterise, firstly, the air-rock transfers at gallery wall, and secondly, the influence of a controlled gallery ventilation on 655 the claystone behaviour. The transfers at gallery wall are considered through the non-classical mixed boundary condition detailed in section 3.3 .2 The same numerical model and material parameters are indeed used hereafter.

Once the excavation front has reached the studied section during the drilling, the gallery is not ventilated yet and the gallery air remains saturated with water vapour (Fig. 7). After the drilling, the ventilation is progressively applied in the underground gallery with a drying of the air which is numerically reproduced by a ventilation initiation phase. During this initiation phase (between 21 and 50 days of simulation), the water pressure in the gallery air decreases from the atmospheric pressure to a value corresponding to the first measurement of air humidity. Then, the air ventilation is applied in the gallery by means of the hygrometric measurements. During the ventilation, the pore water pressure and the water vapour density in the cavity correspond to the relative humidity of the cavity air by Kelvin's law:

$$
R H=\frac{\rho_{v}^{c a v}}{\rho_{v, 0}}=\exp \left(\frac{p_{w}^{c a v} M_{v}}{\rho_{w} R T}\right)
$$

where $\rho_{v, 0}$ is the saturated water vapour density, $M_{v}$ is the water vapour molar mass, $M_{v}=0.018 \mathrm{~kg} / \mathrm{mol}, R$ is the gas constant, $R=8.314 \mathrm{~J} / \mathrm{mol} K$, and $T$ is 


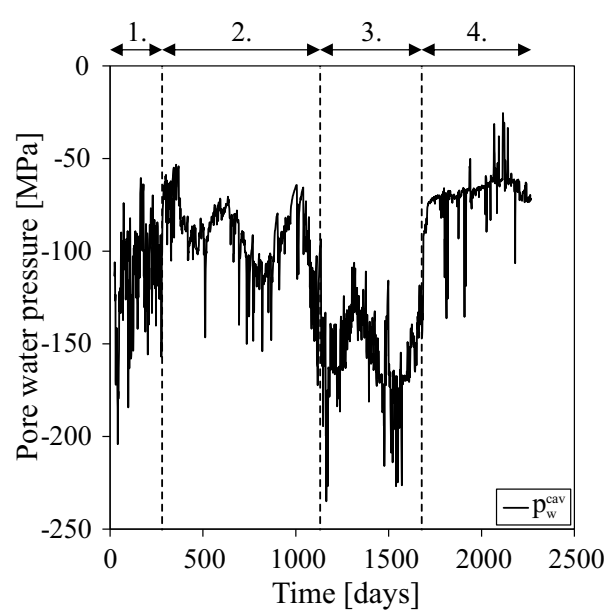

Figure 11: Pore water pressure evolution in the SDZ experimental zone.

660 the absolute temperature expressed in Kelvin. The pore water pressure in the gallery illustrated in Fig. 11 is obtained based on the experimental measurements of temperature and relative humidity (Fig. 2 (b)).

The time evolution of the pore water pressure and of the relative humidity in the gallery are very similar. This is due to the high time variations of relative humidity in comparison to the low variations of temperature in the gallery (Fig. 2 (b)). Therefore, the temperature has only a minor influence on the pore pressure in the experimental zone and it is the relative humidity that mainly influences the water pressure (Fig. 11). Evaluating the impact of relative humidity variations on the rock drainage is one objective of the SDZ ventilation experiment performed by the Andra.

The first result that can be analysed is the claystone progressive drainage which occurs due to the ventilation. In Fig. 12 is illustrated the comparison between numerical results and experimental measurements of pore water pressure evolution in boreholes drilled around the drift (see section 2.2 and Fig. 3). 675 It is obvious that the equilibrium phase of the measure (increase of $p_{w}$ ) is not reproduced by the numerical modelling which starts with the initial pore water pressure value of the clayey rock, $p_{w, 0}=4.5 M P a$. Only the drainage is re- 
produced and has to be compared to experimental values after about 275 days of modelling. A close correspondence is observed between the numerical results and the experimental measurements in the different directions. The pore overpressures observed after the excavation in the vertical direction (Fig. 12 (b)) result of hydro-mechanical couplings mainly related to the anisotropy of the initial stress state. In this direction, the matching with the experimental data is slightly less good which may be related to the lower vertical permeability

${ }_{685}\left(k_{\perp \perp}<k_{\|\|}\right.$, see Table 4$)$ and to the positions of the shear bands that condition the intrinsic permeability evolution.

The vapour mass transfer coefficient (Eq. 21) used to obtain the results of Fig. 12 is of $\alpha=10^{-3} \mathrm{~m} / \mathrm{s}$. This transfer coefficient has indeed an influence on the drainage and its value is chosen to obtain a good reproduction of the experimental data. In the long term, the two controlled ventilation phases (phases (3) and (4) in Fig. 11) do not have a visible effect on the numerical results.

The pore water pressure sensors being unable to acquire negative measurements, other measurements should be taken into account to characterise the EDZ desaturation. The water content $w$ measurements performed around the experimental zone can be used; it is a direct measure of the water saturation degree through the relation $S_{r, w}=\frac{\rho_{s}}{\rho_{w}} \frac{1-\Phi}{\Phi} w$. The numerical and experimental results are illustrated in Fig. 13 (a) for eight boreholes drilled shortly after the excavation (less than 220 days) and in Fig. 13 (b) for five boreholes drilled later (between 2 and 4.25 years). Even if a quite important dispersion of the experimental measurements is visible, a good reproduction is obtained numerically, especially in the short term. An important evolution of the desaturation close to the cavity is reproduced during the excavation and the ventilation initiation phases. In the long term and because of the gallery ventilation, the numerical results highlight a decrease of the water content corresponding to a progressive desaturation. However, it is observed experimentally that the desaturation propagation in the rock is limited after the excavation which may be due to low vapour transfers at gallery wall, to fracture closure or to material sealing 


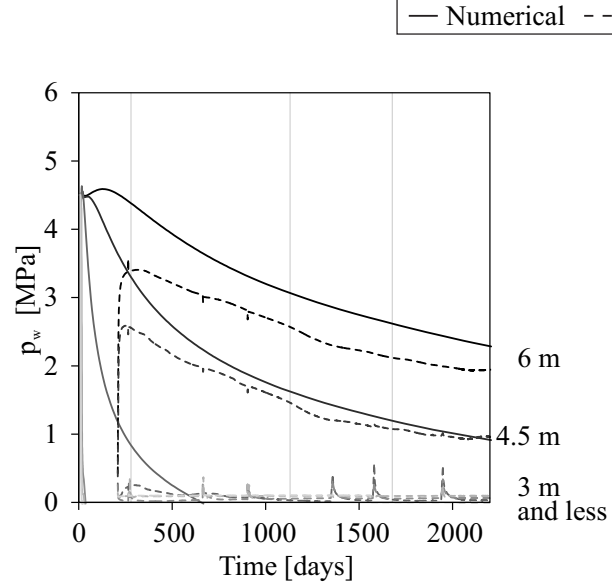

(a)

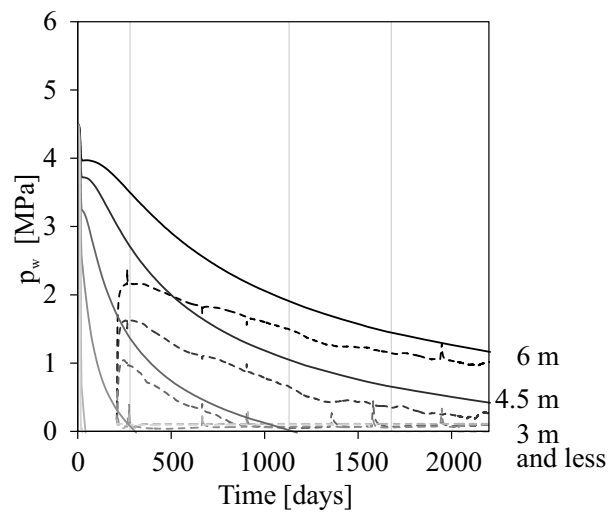

(c)

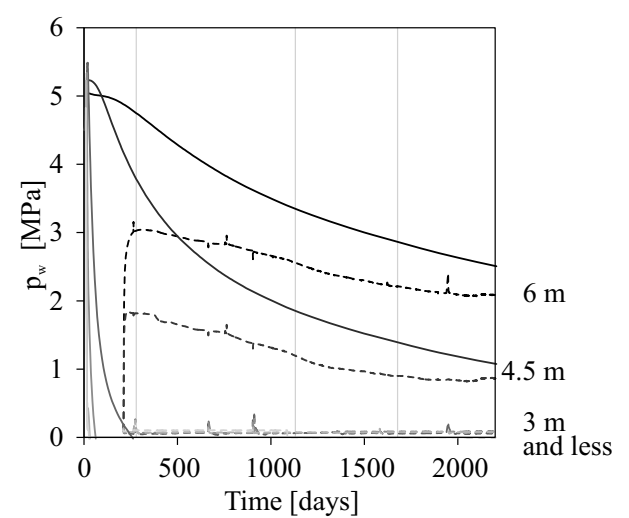

(b)

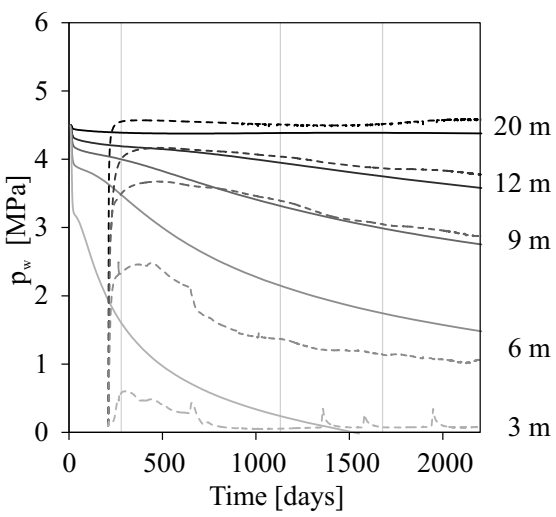

(d)

Figure 12: Pore water pressure evolution in boreholes with comparison to experimental measurements for different distances from gallery wall: (a) oblique at $45^{\circ}$, (b) vertical, and (c,d) horizontal boreholes. 


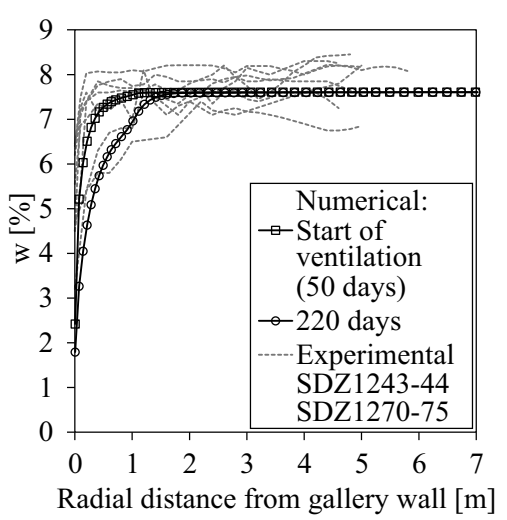

(a)

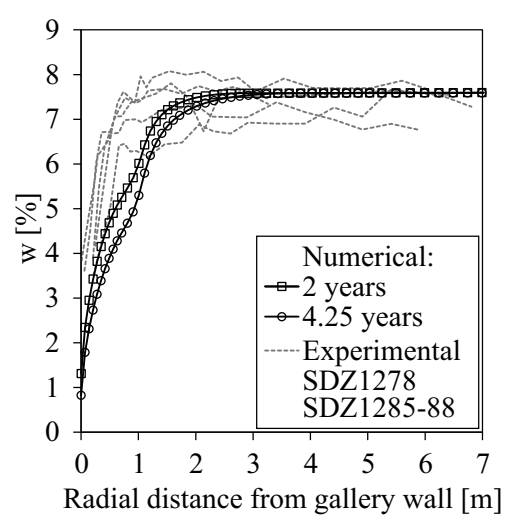

(b)

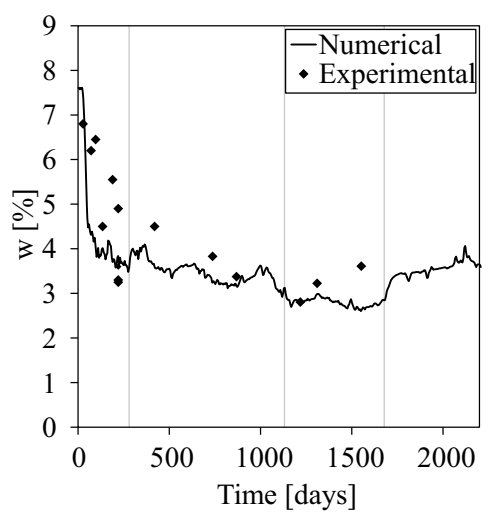

(c)

Figure 13: Water content evolution in the horizontal direction with comparison to experimental measurements: (a,b) in the rock mass in short and long terms and (c) at gallery wall.

/ healing. These two last phenomena are not addressed in the present analy-

710 reserve.

The evolution of the water content at gallery wall is also represented in Fig. 13 (c). The experimental values correspond to the measurements performed the closest to the gallery wall for each borehole. For three of them (SDZ1285

715 to 87), the first samples were taken at about $25 \mathrm{~cm}$ depth therefore the water content values have been corrected. A good reproduction of the desaturation is obtained. Besides, the effect of the controlled ventilation phases is more pronounced on the numerical results of water content at gallery wall than it was on the pore water pressure in the rock mass. In fact, the ventilation effect the permeability is important and where desaturation occurs. A decrease of water content is observed on the numerical results during the ventilation phase with $R H=30 \%$ (phase (3) between 1130 and 1680 days), with values around $w=2.8 \%$ corresponding to $S_{r, w}=0.4$. An increase is observed during the 725 last phase with $R H=60 \%$ (phase(4)), with values around $w=3.6 \%$ and $S_{r, w}=0.5$. Rock resaturation is thenceforward not observed for the considered 
values of imposed relative humidity.

In addition to the permeability evolution in the EDZ, the drainage kinetics in the rock formation is significantly conditioned by the air-rock interaction and the transfers at gallery wall. The evolutions of the different flows and of the cumulative total flow are represented in Fig. 14 for the complete gallery (total circumference).

Let us first consider the seepage flow $\bar{S}$. During the excavation, the claystone is initially fully saturated; then, once the pore water pressure decreases in the gallery air (between 6 and 8 days, Fig. 7), it becomes smaller than the pore water pressure in the rock which engenders a seepage flow directed towards the gallery (Fig. 14 (a)). After the excavation, the ventilation is applied and the pore water pressure in the rock decreases progressively. It leads to a desaturation of the gallery wall $\left(p_{w}^{r}<p_{a t m}\right)$ which cancels the seepage flow (Fig. 14 (a) and (b)). On the other hand, the evaporation flow $\bar{E}$ remains low during the excavation, as long as the rock at gallery wall remains saturated (Fig. 14 (a)). Once the ventilation is initiated, the gallery wall desaturates and a vapour flow directed towards the gallery to ensure thermodynamic equilibrium appears. During the ventilation initiation phase (between 21 and 50 days) the pore water pressure 745 in the gallery air decreases from the atmospheric pressure to about -130 MPa. This generates important gradients and a rapid increase of the evaporation flow. Later, the vapour exchange decreases until the equilibrium is reached between the air and the rock (Fig. 14 (b)).

The two transfer processes are decoupled in the sense that the total flow $\bar{q}$ corresponds to the seepage during the excavation, while the rock at gallery wall remains fully saturated, and to the vapour flow during the ventilation. In the long term, the hydraulic exchanges as well as the progressive drainage are therefore dominated by the evaporation process and the cumulative total flow is mainly composed of water vapour. The liquid water exchange occurs only during the excavation period and has therefore only a minor influence on the progressive rock drainage and desaturation. A boundary condition at gallery wall without liquid water flow might probably lead to similar results in the long 
term. The vapour mass transfer coefficient $\alpha$ controlling the vapour transfer at gallery wall has indubitably a significant influence. A low value implies low vapour transfers and low rock desaturation, while a high value implies important vapour transfers, drainage, and desaturation of the rock.

Once more, the effect of the controlled ventilation phases is noticeable at gallery wall, on the vapour transfers (Fig. 14(b)). The uncontrolled ventilation phase (phase (2) between 280 and 1130 days) displays an average relative humidity of $50 \%$ (Fig. 2(b)); then, when humidity decreases to $30 \%$ in the next ventilation phase, it results in a decrease of $\rho_{v}^{c a v}$ and in an increase of $\bar{E}$ (Eq. 25 and 21. The inverse effect is observed for the last ventilation phase when $R H$ increases.

Another result that can be discussed is the gallery convergence (variation of the gallery diameter). It could have been discussed earlier because most part of the convergence is due to the excavation process but the ventilation and the viscoplasticity have an impact on the long-term convergence. For the considered gallery, the convergences that have been measured in several sections are illustrated in Fig. 15 [86]. Three convergence measurement sections are located in the GED gallery and three in the SDZ experimental zone. The measurements indicate that the convergence is anisotropic with a more important vertical convergence, and that it increases in the long term especially in the vertical direction.

The numerical results in Fig. 15 (a) reproduce fairly well this anisotropic convergence in the short term, mainly thanks to the strain localisation bands located above the gallery. The increase of vertical convergence in the long term is however not well reproduced. This can be explained by the ventilation of the gallery air and the rock desaturation close to the gallery. In fact, under a constant normal total stress at gallery wall and because of the suction imposed 785 by the air ventilation, the compressive effective stress increases in the vicinity of the gallery by Eq. 3. It engenders an elastic unloading close to the gallery which restricts the further plastic deformation [10].

During the relatively short excavation period, the creep deformations seem to 

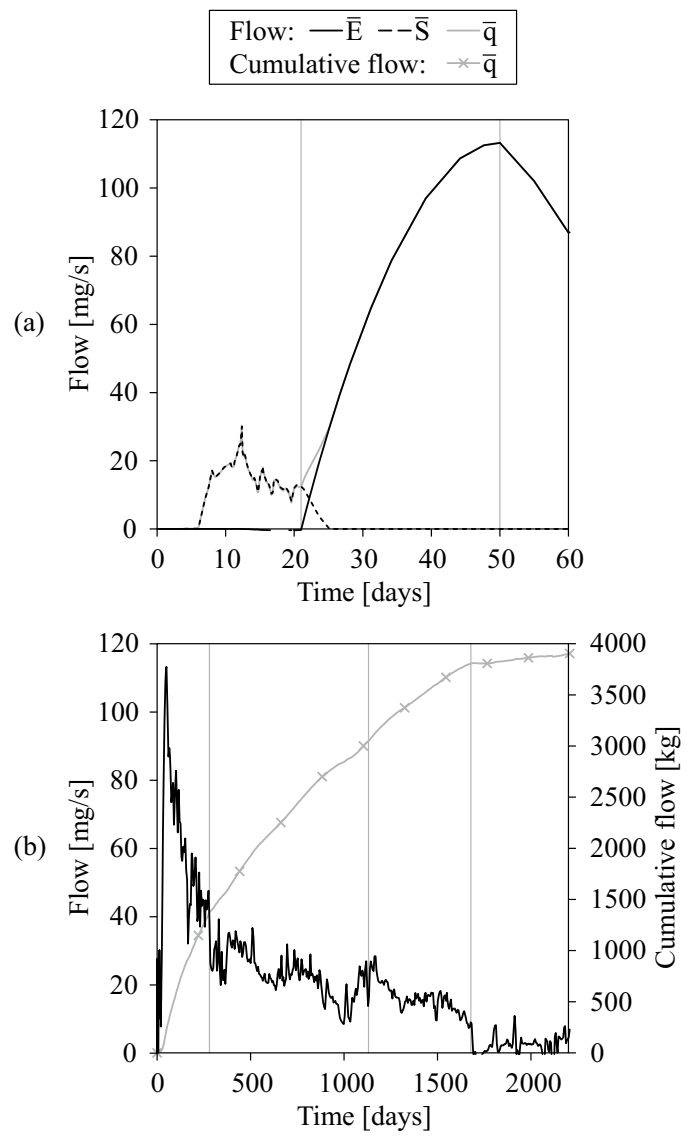

Figure 14: Flows and total cumulative flow evolutions at gallery wall for the complete gallery: (a) in the short term and (b) in the long term. 
(a)

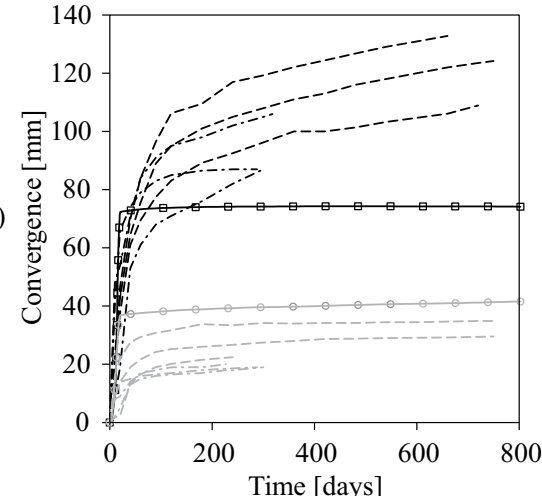

Vertical :

$\rightarrow$ Numerical

- - Experimental

GED A, B, C

-.-Experimental

SDZ D, E, F

Horizontal :

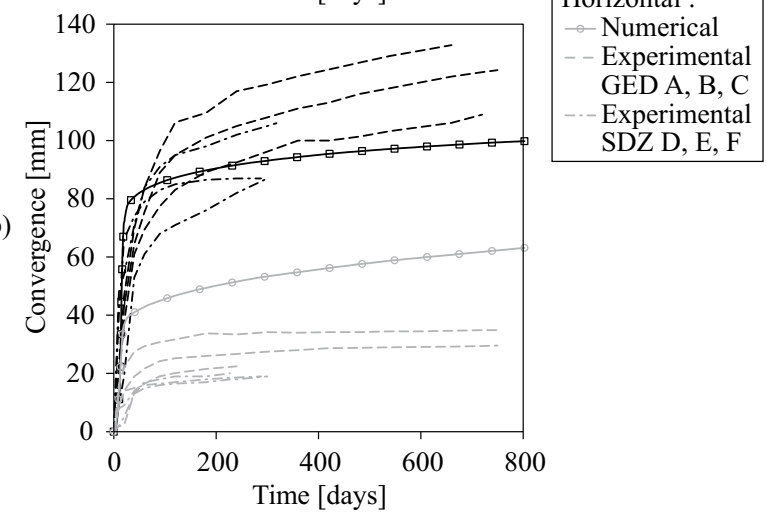

Figure 15: Convergence evolution with comparison to experimental measurements: (a) initial viscoplastic parameters and (b) increase of viscosity.

be negligible, which was also concluded by 7 for a modelling of shaft excavation

in Callovo-Oxfordian claystone. Nevertheless, the viscosity and creep behaviour have an impact on the long-term deformations. It is therefore possible to increase the long-term convergence by adjusting the viscoplastic parameters (Table 3). For instance, modifying the two following parameters $B^{v p}=5.0 \times 10^{-2}$ and $\zeta=55 \times 10^{3} \mathrm{~J} / \mathrm{mol}$ leads to larger convergences as illustrated in Fig. 15 (b).

The viscoplastic model allows to reproduce the increase of vertical convergence.

Unfortunately, from the results of Fig. 15 (a), it is clear that amplifying the delayed viscoplastic strain will improve the correspondence with in situ measurements in the vertical direction but inevitably deteriorates it in the horizontal direction. 


\section{Conclusions}

The presented study is devoted to the numerical modelling of failure process and hydraulic transfer occurring around underground galleries subjected to air ventilation, in a cross-anisotropic argillaceous rock.

The fractures induced by the excavation process in the vicinity of the gallery are reproduced by shear banding, and the strain localisation is properly modelled by means of a regularisation method. The evolutions of flow transfers and transport properties have been characterised around the underground drift, especially in the excavation damaged zone. The evolution of intrinsic permeability is addressed by taking into account strain localisation effects and by using a strain-dependent relation that involves plastic strain as well as a restricted part of the elastic strain. At the end of excavation, the permeability increase is of several orders of magnitude in the shear bands as measured experimentally.

The flow transfers in the damaged zone and in the undisturbed material are studied through the modelling of a large-scale gallery air ventilation experiment 815 (SDZ). The air-rock interaction at gallery wall involves both water vapour and liquid water transfers that are implemented with a mixed hydraulic boundary condition. Such condition is relevant for the reproduction of the transfers because an instantaneous equilibrium between the air and the rock may not be assumed beforehand. An equilibrium is reached in the long term by evaporation process during the gallery air ventilation. Regarding the different ventilation phases, it has been observed that the progressive rock drainage is mostly affected by the long-term ventilation, not by the constant ventilation phases of the SDZ experiment.

The numerical results which are presented indicate that a strain localisation approach for the EDZ modelling, linked to an intrinsic permeability evolution, allows to predict the hydraulic transfer in the Callovo-Oxfordian claystone. The hydro-mechanical model accurately reproduces the drainage kinetics of the undisturbed rock mass and the rock desaturation within the EDZ. Moreover, the reproduction of both mechanical and hydraulic aspects with strain localisation 
830

\section{Acknowledgements}

The authors are grateful for financial support from the FRIA-F.R.S.-FNRS, the National Funds of Scientific Research in Belgium.

\section{References}

840

[1] Diederichs MS. Rock Fracture and Collapse Under Low Confinement Conditions. Rock Mech Rock Eng 2003;36(5):339-81.

[2] Tsang CF, Bernier F, Davies C. Geohydromechanical processes in the Excavation Damaged Zone in crystalline rock, rock salt, and indurated and plastic clays - in the context of radioactive waste disposal. Int J Rock Mech

[3] Delay J, Vinsot A, Krieguer JM, Rebours H, Armand G. Making of the underground scientific experimental programme at the Meuse/Haute-Marne underground research laboratory, North Eastern France. Phys Chem Earth 2007;32(1-7):2-18.

850

[4] Andra . Dossier 2005 Argile. Synthesis: Evaluation of the feasibility of a geological repository in an argillaceous formation, Meuse/Haute Marne site. Tech. Rep.; Paris, France; 2005.

[5] Desrues J. Hydro-mechanical coupling and strain localization in saturated porous media. Rev Eur Génie Civ 2005;9(5-6):619-34. 
[6] Plassart R, Fernandes R, Giraud A, Hoxha D, Laigle F. Hydromechanical modelling of an excavation in an underground research laboratory with an elastoviscoplastic behaviour law and regularization by second gradient of dilation. Int J Rock Mech Min Sci 2013;58:23-33.

[7] Jia Y, Bian HB, Duveau G, Su K, Shao JF. Hydromechanical modelling of shaft excavation in Meuse/Haute-Marne laboratory. Phys Chem Earth 2008;33:S422-35.

[8] Levasseur S, Collin F, Charlier R, Kondo D. A micro-macro approach of permeability evolution in rocks excavation damaged zones. Comput Geotech 2013;49:245-52.

${ }_{865}$ [9] Charlier R, Collin F, Pardoen B, Talandier J, Radu JP, Gerard P. An unsaturated hydro-mechanical modelling of two in-situ experiments in Callovo-Oxfordian argillite. Eng Geol 2013;165:46-63.

[10] Pardoen B, Levasseur S, Collin F. Using Local Second Gradient Model and Shear Strain Localisation to Model the Excavation Damaged Zone in Unsaturated Claystone. Rock Mech Rock Eng 2015;48(2):691-714. doi:10. 1007/s00603-014-0580-2.

[11] Gerard P, Charlier R, Chambon R, Collin F. Influence of evaporation and seepage on the convergence of a ventilated cavity. Water Resour Res 2008;44(5):1-16.

${ }_{875}^{872]}$ Ghezzehei TA, Trautz RC, Finsterle S, Cook PJ, Ahlers CF. Modeling coupled evaporation and seepage in ventilated cavities. Vadose Zone J 2004;3(3):806-18.

[13] Pardoen B, Talandier J, Charlier R, Collin F, Radu JP. Hydro and hydromechanical modelling of ventilation test in clayey rocks. In: Mancuso sво C, Jommi C, D’Onza F, editors. Unsaturated Soils: Research and Apघ plications. Berlin Heidelberg: Springer; 2012, p. 325-32. doi 10.1007/ 978-3-642-31343-1_41. 
[14] Emsley S, Olsson O, Stenberg L, Alheid HJ, Falls S. ZEDEX: A Study of Damage and Disturbance from Tunnel Excavation by Blasting and Tunnel

[15] Bossart P, Meier PM, Moeri A, Trick T, Mayor JC. Geological and hydraulic characterisation of the excavation disturbed zone in the Opalinus Clay of the Mont Terri Rock Laboratory. Eng Geol 2002;66(1-2):19-38.

890

[19] Matray JM, Savoye S, Cabrera J. Desaturation and structure relationships around drifts excavated in the well-compacted Tournemire's argillite (Aveyron, France). Eng Geol 2007;90(1-2):1-16.

[20] Mayor JC, Velasco M, García-Siñeriz JL. Ventilation experiment in the Mont Terri underground laboratory. Phys Chem Earth 2007;32(8-14):61628.

[21] Coussy O. Poromechanics. Chichester: John Wiley \& Sons; 2004.

[22] Arson C, Gatmiri B. Thermo-hydro-mechanical modeling of damage in unsaturated porous media: Theoretical framework and numerical study of the EDZ. Int J Numer Anal Meth Geomech 2012;36(3):272-306. 
[23] Shao JF, Duveau G, Bourgeois F, Chen WZ. Elastoplastic damage modeling in unsaturated rocks and applications. Int J Geomech 2006;6(2):119-30.

[24] Taron J, Elsworth D, Min KB. Numerical simulation of thermal-hydrologicmechanical-chemical processes in deformable, fractured porous media. Int J Rock Mech Min Sci 2009;46(5):842-54.

[25] Rutqvist J, Barr D, Datta R, Gens A, Millard A, Olivella S, et al. Coupled thermal-hydrological-mechanical analyses of the Yucca Mountain Drift Scale Test - Comparison of field measurements to predictions of four different numerical models. Int J Rock Mech Min Sci 2005;42(5-6):680-97.

[26] Aydin A, Borja RI, Eichhubl P. Geological and mathematical framework for failure modes in granular rock. J Struct Geol 2006;28(1):83-98.

[27] Borja RI, Aydin A. Computational modeling of deformation bands in granular media. i. geological and mathematical framework. Comput Methods Appl Mech Engrg 2004;193(27-29):2667-98.

[28] Chambon R, Caillerie D, Matsushima T. Plastic continuum with microstructure, local second gradient theories for geomaterials : localization studies. Int J Solids Struct 2001;38(46-47):8503-27.

[29] Pardoen B, Levasseur S, Collin F. Using shear strain localisation to model the fracturing around gallery in unsaturated Callovo-Oxfordian claystone. In: Chau KT, Zhao J, editors. Bifurcation and Degradation of Geomaterials in the New Millennium. Springer Series in Geomechanics and Geoengineering; Springer; 2015, p. 285-91. doi:10.1007/978-3-319-13506-9_41.

[30] Collin F, Pardoen B. Excavation damaged zone modelling in claystone with coupled second gradient model. In: Yang Q, Zhang JM, Zheng H, Yao Y, editors. Constitutive Modeling of Geomaterials. Springer Series in Geomechanics and Geoengineering; Berlin Heidelberg: Springer; 2013, p. 313-7. doi 10.1007/978-3-642-32814-5_42. 
[31] Salehnia F, Collin F, Li XL, Dizier A, Sillen X, Charlier R. Coupled modeling of Excavation Damaged Zone in Boom clay: Strain localization in rock and distribution of contact pressure on the gallery's lining. Comput Geotech 2015;69:396-410. doi:10.1016/j.compgeo.2015.06.003.

[32] Pietruszczak ST, Mróz Z. Finite element analysis of deformation of strainsoftening materials. Int J Numer Meth Engng 1981;17(3):327-34.

[33] Collin F, Levasseur S, Chambon R. Numerical post failure methods in multiphysical problems. Eur J Environ Civ Eng 2009;13(7-8):983-1004.

[34] Cosserat E, Cosserat F. Théorie des Corps Déformables. Paris: Hermann; 1909.

[35] Toupin R. Elastic materials with couple-stresses. Arch Ration Mech An 1962;11(1):385-414.

[36] Chambon R, Caillerie D, Hassan NE. One-dimensional localisation studied with a second grade model. Eur J Mech A-Solid 1998;17(4):637-56.

[37] Collin F, Chambon R, Charlier R. A finite element method for poro mechanical modelling of geotechnical problems using local second gradient models. Int J Numer Meth Engng 2006;65(11):1749-72.

955 [38] Biot MA. General theory for three-dimensional consolidation. J Appl Phys 1941;12(2):155-64.

[39] Lekhnitskii SG. Theory of Elasticity of an Anisotropic Elastic Body. San Francisco: Holden-Day; 1963.

[40] Amadei B. Rock anisotropy and the theory of stress measurements; vol. 2. New York: Springer-Verlag; 1983. Lecture Notes in Engineering Series.

[41] Love AEH. A treatise on the mathematical theory of elasticity. 4th ed. ed.; Cambridge University Press; 1927,. 
[42] Graham J, Houlsby GT. Anisotropic elasticity of a natural clay. Géotechnique 1983;33(2):165-80.

[43] Cheng AHD. Material coefficients of anisotropic poroelasticity. Int J Rock Mech Min Sci 1997;34(2):199-205.

[44] Pardoen B, Seyedi DM, Collin F. Shear banding modelling in crossanisotropic rocks. Int J Solids Struct 2015;72:63-87. doi $10.1016 / j$. ijsolstr.2015.07.012.

[45] Van Eekelen HAM. Isotropic yield surfaces in three dimensions for use in soil mechanics. Int J Numer Anal Meth Geomech 1980;4(1):98-101.

[46] Barnichon JD. Finite Element Modelling in Structural and Petroleum Geology. Ph.D. thesis; Faculté des Sciences Appliquées, Université de Liège; Belgium; 1998.

[47] Pietruszczak S, Lydzba D, Shao JF. Modelling of inherent anisotropy in sedimentary rocks. Int J Solids Struct 2002;39(3):637-48.

[48] Pietruszczak S. Fundamentals of plasticity in geomechanics; chap. 7, Description of inherent anisotropy in geomaterials. Leiden, The Netherlands: CRC Press/Balkema; 2010, p. 133-56.

[49] Pietruszczak S, Mroz Z. Formulation of anisotropic failure criteria incorporating a microstructure tensor. Comput Geotech 2000;26:105-12.

[50] Pietruszczak S, Mroz Z. On failure criteria for anisotropic cohesivefrictional materials. Int J Numer Anal Meth Geomech 2001;25:509-24.

[51] Chen L, Shao JF, Huang HW. Coupled elastoplastic damage modeling of anisotropic rocks. Comput Geotech 2010;37(1-2):187-94.

[52] Perzyna P. Fundamental problems in viscoplasticity. Adv Appl Mech 1966;9:243-377. 
[53] Shao JF, Zhu QZ, Su K. Modeling of creep in rock materials in terms of material degradation. Comput Geotech 2003;30(7):549-55.

[54] Shao JF, Chau KT, Feng XT. Modeling of anisotropic damage and creep deformation in brittle rocks. Int J Rock Mech Min Sci 2006;43(4):582-92.

[55] Zhou H, Jia Y, Shao JF. A unified elastic-plastic and viscoplastic damage model for quasi-brittle rocks. Int J Rock Mech Min Sci 2008;45(8):1237-51.

[56] Mindlin RD. Second gradient of strain and surface-tension in linear elasticity. Int J Solids Struct 1965;1:417-38.

[57] Collin F, Caillerie D, Chambon R. Analytical solutions for the thick-walled cylinder problem modeled with an isotropic elastic second gradient constitutive equation. Int J Solids Struct 2009;46(22-23):3927-37.

[58] Kotronis P, Collin F, Bésuelle P, Chambon R, Mazars J. Local Second Gradient Models and Damage Mechanics: 1D Post-Localization Studies in Concrete Specimens. In: Exadaktylos G, Vardoulakis I, editors. Bifurcation, Instabilities and Degradation in Geomechanics. Springer; 2007, p. $127-42$.

[59] van Genuchten MT. A closed-form equation for predicting the hydraulic conductivity of unsaturated soils. Soil Sci Soc Am J 1980;44(5):892-8.

[60] Andra . Dossier 2005 Référentiel du site Meuse/Haute-Marne tome 2 : Caractérisation comportementale du milieu géologique sous perturbation. Seconde édition; Paris, France; 2005.

[61] Chapuis RP, Aubertin M. On the use of the Kozeny-Carman equation to predict the hydraulic conductivity of soils. Can Geotech J 2003;40(3):61628.

[62] Pardoen B, Levasseur S, Collin F. Excavation damaged zone modelling including hydraulic permeability evolution in unsaturated argilaceous rock. In: Khalili N, Russell AR, Khoshghalb A, editors. Unsaturated 
Soils: Research and Applications. London: CRC Press; 2014, p. 1387-93. doi $10.1201 / \mathrm{b} 17034-203$.

[63] Maleki K, Poya A. Numerical simulation of damage-permeability relationship in brittle geomaterials. Comput Geotech 2010;37(5):619-28.

[64] Chaboche JL, Lemaitre J. Mécanique des matériaux solides. Paris: Dunod; 1985.

[65] Kachanov LM. Time of the rupture process under creep conditions. Izv Akad Nauk SSR Otd Tech Nauk 1958;8:26-31.

[66] Krajcinovic D. Damage mechanics. North-Holland; 1996.

[67] Dormieux L, Kondo D. Approche micromécanique du couplage permeabilité endommagement. C R Mecanique 2004;332(2):135-40.

[68] Barthélémy JF. Effective permeability of media with a dense network of long and micro fractures. Transp Porous Med 2009;76(1):153-78.

[69] Olsson R, Barton N. An improved model for hydromechanical coupling during shearing of rock joints. Int J Rock Mech Min Sci 2001;38(3):317-29.

1030 [70] Witherspoon PA, Wang JSY, Iwai K, Gale JE. Validity of cubic law for fluid flow in a deformable rock fracture. Water Resour Res 1980;16(6):1016-24.

[71] Snow DT. Anisotropic Permeability of Fractured Media. Water Resour Res 1969;5(6):1273-89.

[72] Liu J, Elsworth D, Brady BH. Linking stress-dependent effective porosity and hydraulic conductivity fields to RMR. Int J Rock Mech Min Sci 1999;36(5):581-96.

[73] Chen Y, Zhou C, Sheng Y. Formulation of strain-dependent hydraulic conductivity for a fractured rock mass. Int J Rock Mech Min Sci 2007;44(7):981-96. 
[74] Olivella S, Alonso EE. Gas flow through clay barriers. Géotechnique 2008;58(3):157-76.

[75] Levasseur S, Charlier R, Frieg B, Collin F. Hydro-mechanical modelling of the excavation damaged zone around an underground excavation at Mont Terri Rock Laboratory. Int J Rock Mech Min Sci 2010;47(3):414-25.

1045

[76] Marschall P, Trick T, Lanyon GW, Delay J, Shao H. Hydro-mechanical evolution of damaged zones around a microtunnel in a claystone formation of the Swiss Jura mountains. San Francisco, California: American Rock Mechanics Association; 2008, The 42nd US Rock Mechanics Symposium (USRMS).

1050

[77] Brooks RH, Corey AT. Hydraulic Properties of Porous Media; vol. 3 of Hydrology Papers. Fort Collins, Colorado: Colorado State University; 1964.

[78] Ehlers W, Eipper G. Finite elastic deformations in liquid-saturated and empty porous solids. Transp Porous Med 1999;34(1):179-91.

[79] Pardoen B. Hydro-mechanical analysis of the fracturing induced by the excavation of nuclear waste repository galleries using shear banding. Ph.D. thesis; Faculté des Sciences Appliquées, Université de Liège; Belgium; 2015.

[80] Nasrallah SB, Perre P. Detailed study of a model of heat and mass transfer during convective drying of porous media. Int J Heat Mass Transfer 1988;31(5):957-67.

[81] Léonard A, Blacher S, Marchot P, Pirard JP, Crine M. Convective drying of wastewater sludges: Influence of air temperature, superficial velocity and humidity on the kinetics. Dry Technol 2005;23(8):1667-79.

[82] Panet M, Guenot A. Analysis of convergence behind the face of a tunnel. In: Proceedings of the 3rd International Symposium : Tunnelling 82. Brighton: 
[83] Wang X. Modélisation numérique des problèmes avec localisation de la déformation en bandes de cisaillement. Ph.D. thesis; Université de Liège; Liège; 1993.

[84] Rice JR. The localization of plastic deformation. In: Koiter WT, editor. Theoretical and Applied Mechanics; vol. 1. North-Holland Publishing Company; 1976, p. 207-20.

[85] Rudnicki JW, Rice JR. Conditions for the localisation of deformation in pressure sensitive dilatant materials. J Mech Phys Solids 1975;23:371-94.

[86] Armand G, Noiret A, Zghondi J, Seyedi DM. Short- and long-term behaviors of drifts in the Callovo-Oxfordian claystone at the Meuse/HauteMarne Underground Research Laboratory. J Rock Mech Geotech Eng $2013 ; 5(3): 221-30$. 